\title{
Deficits in lexical and semantic processing: Implications for models of normal language
}

\author{
JENNIFER R. SHELTON and ALFONSO CARAMAZZA \\ Harvard University, Cambridge, Massachusetts
}

\begin{abstract}
The investigation of language processing following brain damage may be used to constrain models of normal language processing. We review the literature on semantic and lexical processing deficits, focusing on issues of representation of semantic knowledge and the mechanisms of lexical access. The results broadly support a componential organization of lexical knowledge-the semantic component is independent of phonological and orthographic form knowledge, and the latter are independent of each other. Furthermore, the results do not support the hypothesis that word meaning is organized into modality-specific subcomponents. We also discuss converging evidence from functional imaging studies in relation to neuropsychological results.
\end{abstract}

The investigation of cognitive deficits in brain-damaged individuals can provide powerful constraints for theories of normal cognition. Brain damage does not lead to an undifferentiated loss of cognitive abilities but to richly structured patterns of impaired and spared performance. Thus, for example, a patient might show severe difficulties in orally producing the names of pictures but show no comparable difficulties in writing them. Or a patient might show great difficulty in producing nouns but not verbs and adjectives. Furthermore, in most cases impaired performance deviates from normal performance in instructive ways. For example, in a picture naming task a patient might produce phonological distortions of the target response (e.g., chair $\rightarrow$ "share, chail"), suggesting the possibility that the correct lexical node has been accessed but that subsequent processes are damaged. Or the patient might produce well-formed, semantically related responses (e.g., chair $\rightarrow$ "table, not that but close, something you sit on"), suggesting that motor programming and articulatory processes are intact but that lexical selection mechanisms are malfunctioning. The analysis of the dissociation and association of symptoms and their related error patterns severely constrains possible interpretations of the locus of functional impairment in the normal language production system. The logic of inferences from impaired performance to normal cognition is straightforward: We prefer a theory of normal cognition over alternative theories if that theory can explain both normal performance and the various ways in which a system breaks down in conditions of brain damage. One area

This review was supported in part by NIH Grant NS22201. We thank Randi Martin, Michael Cortese, Matt Lambon Ralph, and two anonymous reviewers for their helpful suggestions on an earlier version of the manuscript. Correspondence should be addressed to J. R. Shelton or A. Caramazza, Cognitive Neuropsychology Laboratory, Department of Psychology, Harvard University, 33 Kirkland St., Cambridge, MA 02138 (e-mail: caram@wjh.harvard.edu or jshelton@wjh.harvard. edu). that has benefited greatly from neuropsychological investigations is lexical processing.

A basic assumption shared by almost all current theories of the lexicon is that it is composed of several distinct components. This assumption supports the expectation that brain damage could result in the selective disruption of each of the components that constitutes the lexical system. The ways in which a cognitive system can be damaged depends on how it is organized in the brain. Functionally independent lexical components can be damaged selectively only if they are neuroanatomically separable. ${ }^{1}$ But, within the constraints imposed by the neuroanatomical organization of the lexical system and the vagaries of damage to different regions of the brain (as imposed, e.g., by the organization of the vascular system in the brain in cases of cerebrovascular accidents), the patterns of lexical impairments should reflect the functional organization and computational structure of the lexical system (Caramazza, 1986; Shallice, 1988). This basic expectation has received ample support in the neuropsychological literature and has encouraged detailed investigations aimed at uncovering the processing structure of the lexical system.

In this paper, we review recent results in the area of lexical processing by aphasic patients and show that the data provide crucial constraints for models of normal language processing. Because the cognitive neuropsychological literature has become quite extensive, we focus on just two issues: the structure of the semantic component and the organization of lexical form subsystems. We begin by considering some basic assumptions about the structure of the lexicon.

\section{OVERVIEW OF THE LEXICAL SYSTEM}

Consider the lexical system sketched in Figure 1. This diagram presents a set of interconnected, independent components and is representative of a number of different theories of the functional architecture of the lexical 


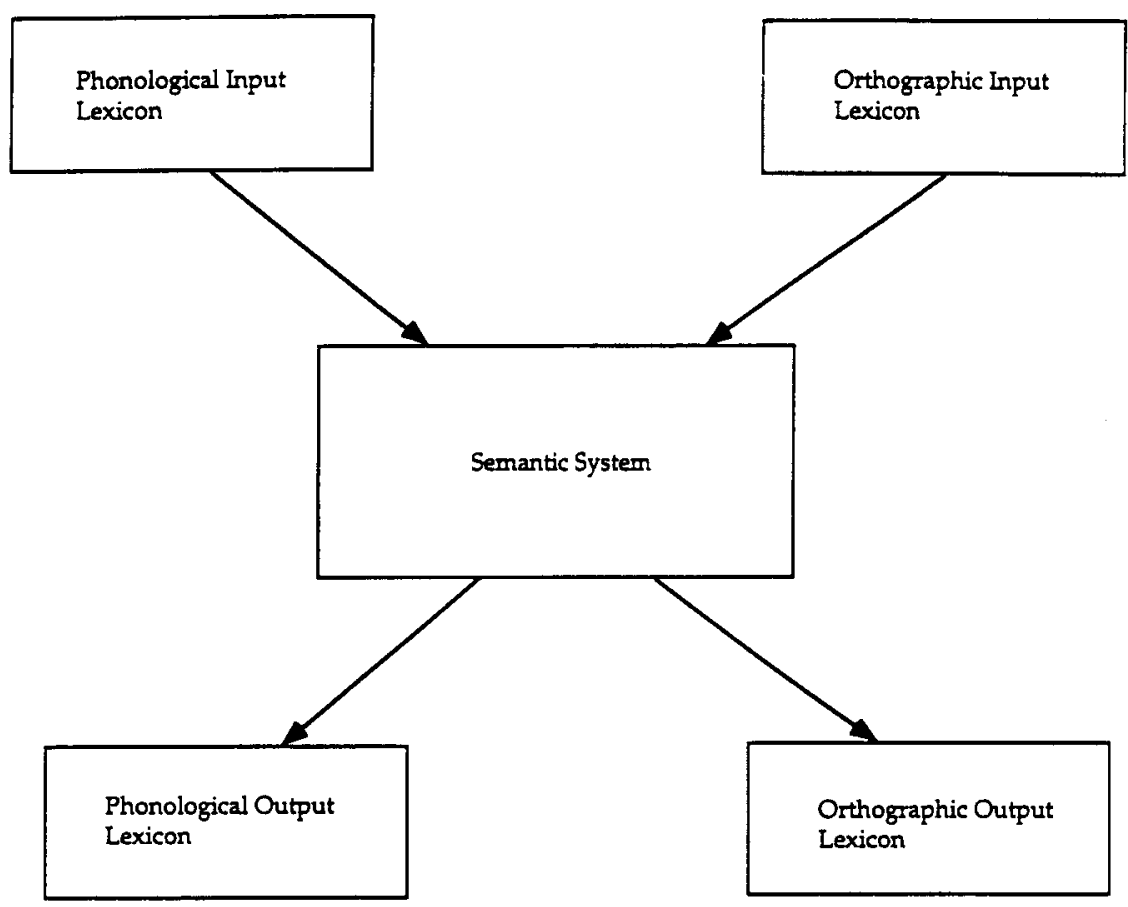

Figure 1. A general overview of the lexical system.

system (e.g., Caramazza, 1986; Dell, 1988; Levelt, 1989; Morton, 1981; Shallice, 1988). There are several important points to be made about this diagram. First, input and output components are represented independently. There have been numerous debates concerning this issue (see, e.g., Allport, 1984; Howard \& Franklin, 1988; Monsell, 1987), which do not need to be reviewed here other than to say that to date the results that have been cited in support of separate input and output processing components can usually be accommodated by models specifying single processing components (but see Nickels \& Howard, 1994). These components are presented separately here for ease of exposition since areas relevant to input and output processing will be reviewed separately.

Each lexical form component is assumed to contain the information relevant to a word's representation for either recognition or production, separately for phonological and orthographic processing. Later in the paper, arguments for a separation between phonological and orthographic output components are reviewed. For input, there are theoretical and empirical reasons for separating orthographic and phonological lexical representations: For example, there must be a mechanism by which irregularly spelled words are recognized. That is, "stored" word forms must exist that correspond to those words, such as yacht, soldier, or island, which cannot be pronounced using only a simple phonological conversion strategy. Moreover, some brain-damaged patients read regularly spelled words and pronounceable pseudowords (e.g., plim, garper, burndle) at a significantly higher rate than irregular words, presumably using a phonological con- version procedure (see papers in Patterson, Marshall, \& Coltheart, 1985). In some of these patients, often labeled "surface dyslexics," the impairment is thought to affect the orthographic input lexicon ${ }^{3}$ - that is, the word forms that are stored in this processing component (see also Howard \& Franklin, 1987). Since these patients do not have problems comprehending words from auditory input, the phonological input lexicon is presumed to be undamaged and thus separate from the impaired orthographic input lexicon.

A third aspect of the lexical system represented in Figure 1 is a separation of lexical semantics from lexical input and output processing (for simplicity, they are referred to as "semantic processing" and "lexical processing," respectively). There are numerous examples of why these components should be considered separate processing subsystems. For example, the above description of (one form of) surface dyslexia refers to patients who can successfully process information semantically, at least from phonological input, but who cannot process information in the orthographic input lexicon. There are also examples of patients who can process information in the phonological input lexicon but cannot use this information to successfully access semantic information (see, e.g., Ellis, 1984; Franklin, Howard, \& Patterson, 1994; Kohn \& Friedman, 1986). As noted, there are many reports of patients who have problems processing specific semantic information such as that associated with certain semantic categories, and those deficits are not associated with selective problems of input or output processing. Also discussed below are patients who have problems with 
orthographic and/or phonologic production that result from postsemantic processing deficits and not deficits to the semantic system.

The simplified lexical system presented in Figure 1 does not include the representation of syntactic information. It is assumed that syntactic information is represented separately from semantic and lexical form information. There are numerous examples of patients who can process correctly the meaning of individual nouns and verbs in a sentence but cannot understand the meaning of the sentence as a whole (see, e.g., Caramazza \& Zurif, 1976; Schwartz, Saffran, \& Marin, 1980; for reviews, see Berndt, 1991; Caramazza \& Berndt, 1978). Thus, a patient may be able to tell what girl, boy, and push mean but will be unable to select the appropriate picture to match the sentence "The girl pushes the boy," especially when the choice involves selecting between a picture of a girl pushing a boy or a boy pushing a girl. We are not concerned here with this aspect of syntactic processing (for a review, see Berndt, Mitchum, \& Haendiges, 1996). However, the role of grammatical features of words (e.g., grammatical class, gender, etc.) in lexical access is discussed later in the paper.

There is also neuroanatomical support for the idea that different aspects of language processing are independent of one another. Since the late 1800s it has been known that damage to different areas of the brain could result in different patterns of behavior in language processing (for review, see McCarthy \& Warrington, 1990). Recent advances in functional neuroimaging techniques have allowed researchers to explore in greater detail the neuroanatomical organization of language processing, with results that are beginning to converge with the established neurobehavioral observations. Thus, both behaviorally and neurologically there is evidence for considerable structure and organization in the lexical system.

Even this simple overview provides quite a bit of information from cognitive neuropsychology that constrains models of normal processing: Components can be damaged independently of one another, requiring certain assumptions regarding the organization and representation of knowledge of lexical and semantic information. We turn now to a consideration of several aspects of language processing that have been extensively studied within cognitive neuropsychology, specifically focusing on issues of semantic and lexical output processing and representation. We review several different interpretations and discuss the evidence in favor of certain positions over others, ultimately arriving at what we feel is the most plausible interpretation of the collective body of evidence.

\section{SEMANTIC KNOWLEDGE: UNITARY VERSUS MULTIPLE FORMATS}

The evidence from cognitive neuropsychology shows that the semantic component functions autonomously from other lexical components; it also helps reveal the internal structure of the semantic system. How knowledge is organized within this semantic system can be understood in part by examining the patterns of performance of patients who have deficits to semantic knowledge. Two areas that have received considerable attention concern the issue of modality-specific organization of knowledge and the issue of category-specific knowledge deficits.

\section{Separate Visual and Verbal Semantic Systems?}

A popular view in cognitive psychology and neuropsychology is that different modalities of semantic information are represented independently, and there are a number of models of semantic memory that distinguish between separate representations for "visual" and "verbal" knowledge (e.g., Allport, 1985; A. R. Damasio, 1990; Paivio, 1971; Shallice, 1988; Warrington \& Shallice, 1984). This position has been disputed, however, and certainly does not represent the consensus in the cognitive literature (see Seymour, 1979, for a review). Snodgrass (1984), for example, has suggested that the evidence from normal subjects does not strongly favor one view over the other.

In the neuropsychological literature, many researchers have adopted a multiple-modality view of semantic memory. For example, Shallice $(1987,1988,1993)$ presented several lines of evidence from brain-damaged subjects that he interpreted as supporting the existence of independent, modality-specific representations of knowledge. A schematic representation of this position is presented in Figure 2. As can be seen, visual knowledge and verbal knowledge are represented independently of each other and the bidirectional arrows between the two representations indicate that the two types of knowledge interact with each other. Furthermore, structural descriptions of objects directly access visual semantic knowledge, whereas verbal semantic knowledge about objects is mediated by access to visual semantic knowledge. Likewise, verbal input descriptions (phonological or orthographic lexical forms) directly access verbal semantic knowledge, and access of visual semantic knowledge about an item from verbal input is mediated by access to verbal semantic knowledge. ${ }^{4}$ Shallice and others (e.g., Beauvois, 1982; Warrington \& Shallice, 1979; see Saffran \& Schwartz, 1994, for a review) have presented several lines of evidence in favor of the multiple-semantics position, including the performance of patients with "optic aphasia" (and other "modality-specific" anomias) and the performance of patients with semantic memory impairments.

Modality-specific anomia refers to a disorder characterized by naming difficulties restricted to stimuli presented in one modality (naming from other input modalities is unimpaired). Such disorders are distinguished from agnosia (disorders in recognizing objects shown in one modality) by the fact that anomic patients can access some semantic information in the impaired input modality (Shallice, 1987, 1988). For example, patients with "tactile aphasia" cannot name from tactile input but can mimic the use of the unnamed object when blindfolded (e.g., 

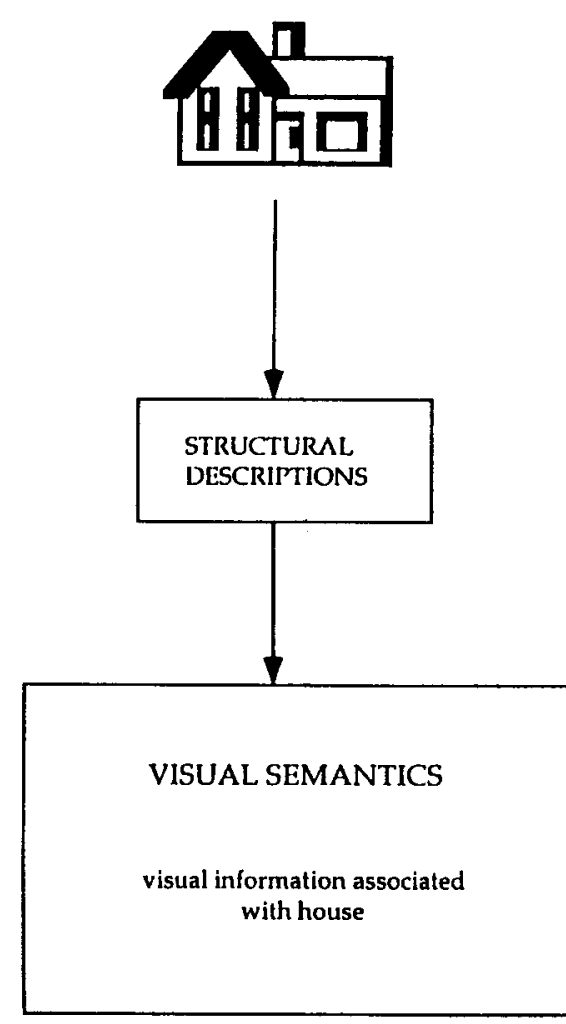

house |haus

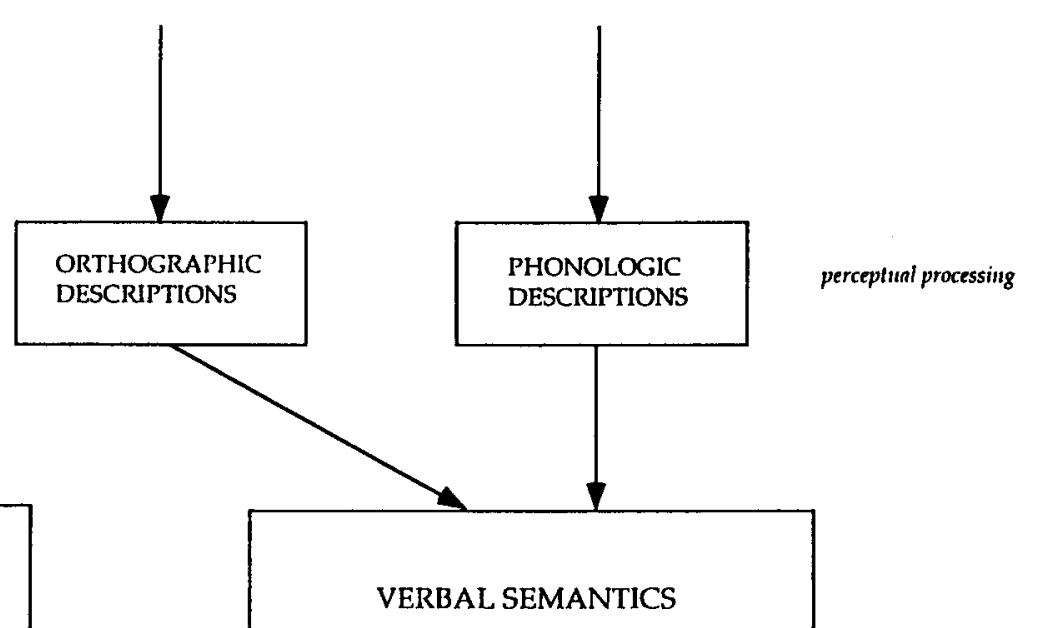

semantic processing

Figure 2. An example of a model postulating separate modality-specific semantic systems.

Beauvois, Saillant, Meininger, \& Lhermitte, 1978). Patient R.G. (Beauvois et al., 1978) was impaired at naming objects presented in the tactile modality $(62.5 \%$ correct $)^{5}$ but virtually unimpaired at naming from either the visual or the auditory modality $(96 \%$ and $98.8 \%$, respectively). R.G. also demonstrated appropriate handling and use of objects he could not name from the tactile modality, indicating that he could understand what the object represented (i.e., he could access the "correct" semantics from tactile input).

There are also reports of patients with impairments to other input modalities. Patients have been described who demonstrated impaired naming from visual input but unimpaired naming from auditory and tactile input (see, e.g., Coslett \& Saffran, 1989, 1992; Hillis \& Caramazza, 1995a; Lhermitte \& Beauvois, 1973; Riddoch \& Humphreys, 1987); others have been described who demonstrated impaired naming from auditory input but not visual or tactile input (Denes \& Semenza, 1975). For example, E.M. was described as a case of "optic aphasia" (Coslett \& Saffran, 1992). E.M. was impaired at naming objects presented visually $(6 / 28=21 \%)$ and significantly better at naming the same objects presented for touch $(17 / 25=68 \%)$ and when naming the item to description $(19 / 28=68 \%)$. E.M. provided appropriate gestures for visually presented objects ( $100 \%$ correct) and performed well on semantic classification tasks with visual input (e.g., 31/32 = 97\% judging functional similarity). Coslett and Saffran interpreted this pattern of performance as indicating that E.M. could access unimpaired semantic information from the impaired input modality.

Other patients have been described who were significantly more impaired in one input modality over another (Warrington, 1975) but who were not classified as "modality-specific" aphasics. One of Warrington's patients, E.M., (a different case from that described above), was more impaired in making semantic decisions from verbal $(70 / 120=58 \%)$ than from visual input $(93 / 120=$ $78 \%$ ), whereas the other patient, A.B., showed the opposite pattern (verbal input: $80 / 120=75 \%$, visual input: $75 / 120=63 \%$ ). In another case (Schwartz, Marin, \& Saffran, 1979), W.L.P. could correctly demonstrate the use of objects $(100 \%)$ but was unable to identify the words associated with those objects $(89 / 140=64 \%$, where chance $=50 \%$ ).

Some investigators have interpreted the patterns of dissociations found in these patients as providing support for a multiple-semantics view of knowledge representation (e.g., Beauvois et al., 1978; Coslett \& Saffran, 1989, 1992; Shallice, 1988). They argued that the observed dissociations result from the patients' failure to access an intact verbal semantic system from an equally intact modality-specific semantic system (visual or tactile). Thus, in the case of optic aphasia, the visual seman- 
tic system was assumed to be intact since the patients were supposedly able to access semantic information from visual input (as indicated, e.g., by the ability to mime the action associated with objects that could not be named). Given this assumption, the optic aphasic's failure to name is argued to result from an inability to transmit information from the visual-semantic system to the verbal semantic system, which is required for naming. This reasoning has been applied to all sensory modality-specific anomias/aphasias (e.g., Allport, 1985, proposed a model of semantics that represents semantic information separately for each sensory modality).

A second source of evidence cited in favor of separate visual and verbal semantic systems comes from patients who show priming in one modality but not another. Warrington and Shallice (1979) described a patient, A.R., who could read words significantly better when they were preceded by an auditory prompt than when the same words were preceded by pictures. For example, A.R. was significantly better at reading pyramid when he heard the word "Egypt" prior to presentation of the target $(49 / 80=$ $61 \%)$ than when he saw a picture of a pyramid $(36 / 80=$ $45 \%$ ). Furthermore, A.R.'s picture naming improved only slightly when the target was preceded by an auditory prompt. Given the lack of priming from pictures to words and from words to pictures, Warrington and Shallice (1979) argued that A.R. could not transmit information from visual semantics to verbal semantics.

Taken together, the reported cases would seem to present strong evidence in favor of separate visual and verbal semantic systems (and presumably other sensory input systems) that can be selectively affected following brain damage. However, these interpretations and explanations have not gone unchallenged, and there are several grounds on which researchers have objected to the distinction between a visual semantic system and a verbal semantic system, or, more generally, modality-specific semantic systems (e.g., Caramazza, Hillis, Rapp, \& Romani, 1990; Hillis, Rapp, Romani, \& Caramazza, 1990; Humphreys \& Riddoch, 1988; Riddoch \& Humphreys, 1987; Riddoch, Humphreys, Coltheart, \& Funnell, 1988).

Riddoch et al. (1988) questioned whether the difficulty levels of the naming and comprehension tasks used in the studies of modality-specific anomias were equivalent across the different modalities, since naming from pictures and naming tactilely from real objects could very well be of unequal difficulty given that more information might be available from real objects than from pictures. Other aspects of the tasks used in different modalities could also have made them of unequal difficulty. For example, miming and forced-choice tasks may be accomplished successfully on the basis of partial semantic information in pictures and real objects. Riddoch and Humphreys (1987) described J.B., a patient with "optic aphasia" who was impaired at naming objects in the visual modality $(20 / 44=45 \%)$ but who could name those objects better from the tactile modality $(33 / 44=75 \%)$. Like other reported cases of optic aphasia, J.B. also showed better miming than naming of objects from visual input $(33 / 44=75 \%)$. However, J.B. was impaired at answering detailed semantic questions about visually presented objects $(177 / 284=62 \%)$, indicating that he could not fully access semantics from visual input. Riddoch and Humphreys suggested that J.B. had impaired visual input processing that resulted in poor access of semantic information from this input modality. This pattern of results does not require distinguishing between visual and verbal semantics.

More recently, Hillis and Caramazza (1995a) described a patient (D.H.Y.) with "optic aphasia" whose pattern of performance was similar to previously reported cases. D.H.Y. could not name from visual input $(2 / 47=4 \%)$ but could name from other input modalities (e.g., tactile input: $44 / 47=94 \%$ ), and she demonstrated access to semantic knowledge from visual input by performing very well on a number of semantic processing tasks, including those tasks previously used to demonstrate "intact" semantic knowledge in a case of optic aphasia (E.M.; Coslett \& Saffran, 1992). However, the appropriateness of these semantic processing tasks for assessing the integrity of the semantic system was questioned since tasks such as miming or classification into semantic categories (animal vs. plants) do not necessarily require detailed semantic analysis or an appreciation of the subtle differences between semantically related items. When D.H.Y. was tested on semantic processing tasks that required appreciation of detailed semantic information, she performed much more poorly $(50 \%-88 \%$ correct) and displayed strong evidence that she was not able to get sufficient semantic information from the pictures to allow her to perform the tasks normally. For example, on tasks that required D.H.Y. to sort animals by function (e.g., "Is it edible?"), answer detailed questions about pictured items, or pick the two most related pictures from three related items (e.g., lightswitch, lightbulb, traffic light), D.H.Y. performed well below the normal range. However, D.H.Y. performed normally on these same tasks when the semantic information was probed in nonvisual modalities. Much like J.B. (Riddoch \& Humphreys, 1987), this case clearly showed that access to semantics from the impaired input modality was not normal. Taken together, J.B. and D.H.Y.'s patterns of performance raise the possibility that at least in some cases, the tasks used to probe semantic knowledge were not sensitive enough to pick up subtle semantic deficits (or complete access to this knowledge) since the tasks could have been performed at a high level of accuracy using incomplete semantic information.

Objections have also been raised against studies that compared performance between semantic knowledge tasks with pictures versus verbal stimuli on the grounds that there is information in the pictures that could allow patients to answer questions by relying on structural cues found in pictures but not in verbal input (Caramazza et al., 1990; Riddoch et al., 1988). ${ }^{6}$ For example, there is a great deal of information in a picture of a cat that would allow answers to questions about that object, but there is noth- 
ing in the phonological or orthographic form of the name of that object that would give clues about its semantic content. The fact that a picture of a cat represents semantic information such as eyes, a mouth, and four legs could be enough to allow a patient to discern that the object represented a living thing and was a nonhuman mammal (because of the presence of four legs). Further, that information could lead patients to deduce that the animal would have fur and would be capable of self-initiated movement. All this information would be available through the understanding of certain features represented in the picture even without a complete understanding of the object.

There is also empirical evidence that is highly problematic for the modality-specific semantics theory. Hillis et al. (1990) reported the performance of a patient, K.E., who showed similar levels of performance $(36 \%-$ $47 \%$ correct) across a wide variety of tasks differing in terms of input and output requirements. Since virtually all of K.E.'s errors $(60 \%-96 \%)$ across all tasks were semantic substitutions (tiger $\rightarrow$ "lion"), the pattern of performance suggested a deficit at the semantic level. And, since the level and type of difficulty was comparable across almost all tasks and modalities, K.E.'s performance was interpreted as indicating that the damage involved a single semantic system shared in all tasks.
Several researchers have argued that the modalityspecific aphasia cases could be easily interpreted within a single amodal semantic system (e.g., Caramazza et al., 1990; Hillis \& Caramazza, 1995a; Riddoch et al., 1988). For example, Caramazza et al. (1990) presented a modalityneutral model of semantic memory, the "organized unitary content hypothesis" (OUCH), and demonstrated that it could account for the patterns of performance that originally motivated a multimodal semantic memory theory. A schematic representation of this type of amodal semantic memory model is shown in Figure 3.

Two assumptions in this model are relevant here. The first is the assumption of "privileged accessibility." This assumption captures the fact that there is an asymmetry in the relationships that words and objects have to semantic information: Words but not pictured objects have an arbitrary relationship to their meanings (e.g., dog and $\log$ are lexically very similar but have radically different meanings). The relationship between pictures (or perceptual features in general) and semantics is not arbitrary (e.g., a chair has a flattish surface that is used for sitting). Thus, perceptual features can be interpreted semantically with the consequence that the surface properties of pictures or objects provide much more semantic information than do words.
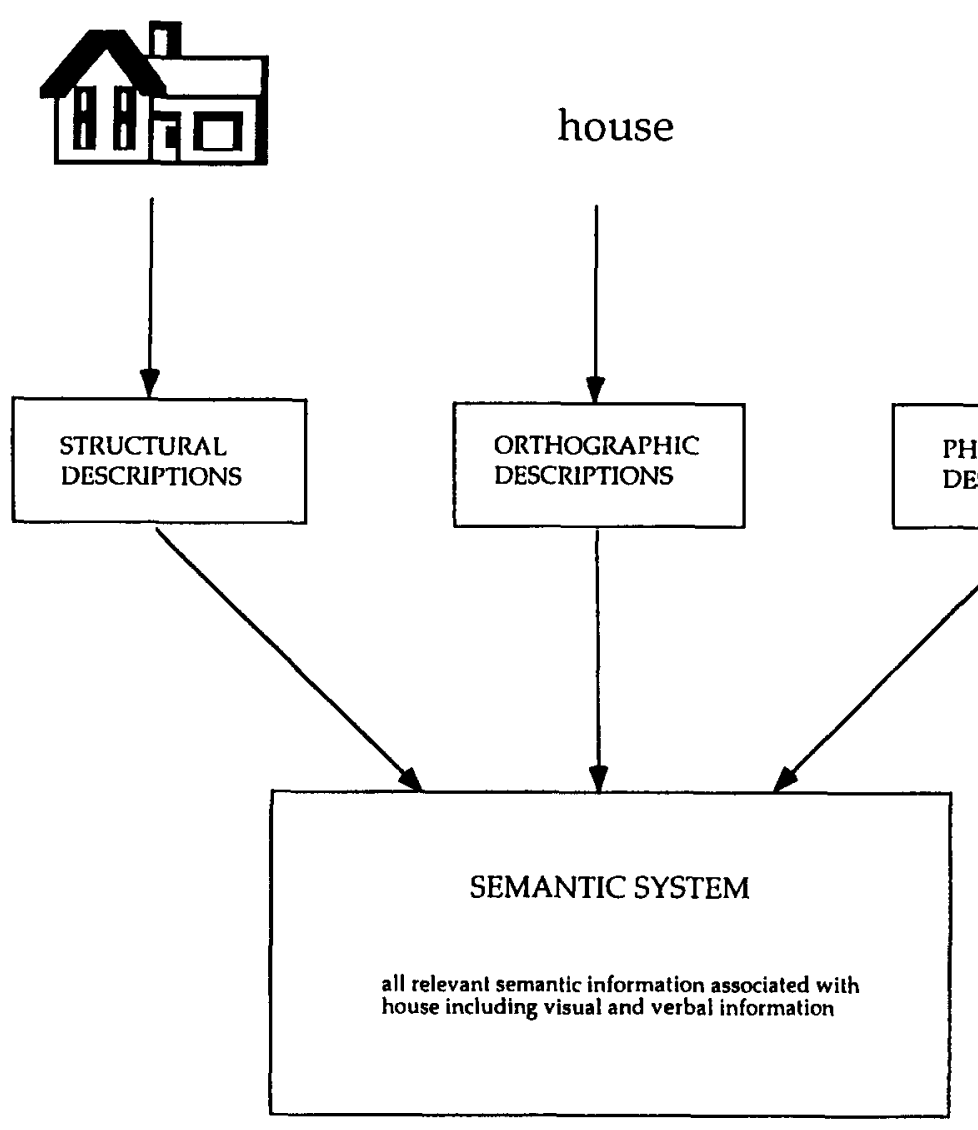

house |haus

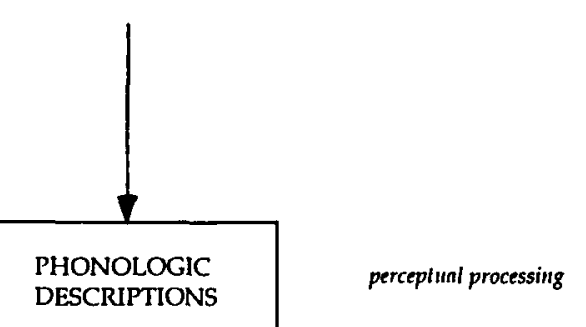

Figure 3. An example of a model postulating a single, amodal semantic system. 
A second assumption of the model - the assumption of "privileged relationships"-is that there is a special relationship between types of semantic information associated with an object such that certain semantic features (e.g., chairs have a flattish surface) are more strongly linked to certain semantic features of that object (e.g., chairs are used for sitting) than to others (e.g., chairs are found in houses). And, it could be argued that the action associated with an object may have a privileged relationship with certain perceptual features of that object (e.g., a handle). As a consequence, miming in response to an object or a picture could have been readily accomplished despite the fact that naming of that object is impaired, since naming of the object requires more information than that required to support miming the action of the object. And, obviously, there is no information in the surface structure of a word, unlike the case of the picture, to support miming. This second assumption applies not only to form-function relationships but also to any features of objects that are highly intercorrelated (see also McRae, de Sa, \& Seidenberg, 1997, for a similar proposal). That is, certain properties of objects (e.g., has a mouth) are likely to be highly related to other properties of that object (e.g., is animate, has eyes, ingests food, produces sound).

This model predicts that "optic aphasic" patients should show impaired performance on tasks requiring detailed semantic knowledge, since they presumably have difficulty accessing a complete semantic representation (in a single semantic system) from visual input. Getting to semantic information is not impossible from the impaired input modality, as shown by the fact that these patients can perform some semantic processing tasks even when items are presented to the impaired modality (e.g., D.H.Y. and J.B. performed well on the same or similar tasks used to establish "unimpaired" semantics). But, the semantic representation that is accessed is not complete and therefore patients perform poorly with tasks that require the appreciation of detailed semantic information (or, at least, that was the case for D.H.Y. and J.B., who were tested on more extensive, detailed assessments of semantic processing). Thus, previously reported cases of modalityspecific aphasias that have been cited in favor of modalityspecific semantic systems can be accommodated without difficulty within a unitary semantics model.

A model of a single amodal semantic system can also accommodate priming effects and modality-specific comprehension deficits in much the same way as it explains modality-specific aphasias. For example, the patient described earlier, A.R., was much better at reading a word when it was preceded by an auditorily presented related word than when the word was preceded by a picture of the concept represented by the word. Assuming that A.R. has partial damage to a semantic system and that similar semantic information is activated when A.R. sees a word or sees a picture of the concept represented by the word, little additional semantic information is provided by the presence of the picture. However, priming with a semantically related word can activate additional semantic in- formation such that the patient is then able to read the word. Patients do not completely lose all semantic information following brain damage, and thus there is always some information available to them. If the tasks are designed so that providing additional information can improve performance and/or make use of the information that they still retain, the model would predict different levels of performance in different modalities depending on the amount of information provided by the input (see Caramazza et al., 1990; Hillis et al., 1990; Rapp, Hillis, \& Caramazza, 1993, for detailed discussion).

A distinction between visual and verbal semantics is only as helpful as our understanding of what is meant by "visual" and "verbal" semantics. Unfortunately, the multiple-semantics hypotheses have remained rather vague on the precise meaning of these terms, with the consequence that it has been difficult to generate the predictions and interpretations of performance that are needed to further our understanding of "modality-specific" semantic information. Consider the role that modality might play in the acquisition of concepts. The function of an object is experienced visually (or perhaps in other sensory modalities), yet this knowledge is assumed to be represented in the "verbal" semantic system. So, for example, we learn the function of a fork by watching someone use this item (and presumably through sensory feedback of ourselves using the item as well), which would suggest that function should be a property of the "visual" semantic system. Or, conversely, without having seen (or heard, or touched) a porcupine, we can read that this animal has long quills extending out of its body that are sharp and pointy. Although we haven't experienced this information through sensory modalities, it is considered sensory information, and thus should be stored in the corresponding sensory semantic systems. If this is the case, we are left with trying to explain how information that is experienced through one modality in acquisition is stored in the appropriate modality-specific semantic system based on the "modality" of the information and not the modality of the input.

In contrast to the hypothesis that the data require the existence of separate visual and verbal semantic systems, the unitary semantics hypothesis - OUCH-reviewed here can provide a principled explanation for all the reported cases (see also Riddoch et al., 1988) by making plausible assumptions about the structure of access to semantic information and by assuming that the organization of that information is based on the meanings of concepts. Moreover, this account does not need special assumptions regarding learning mechanisms that would require information to be "placed" in a specific system depending on, we guess, the nature of that information (regardless of the modality through which that information is acquired). Therefore, the neuropsychological literature does not support a multiple-semantics position.

Also, results from a neuroimaging study with PET that directly compared semantic processing of words and pictures, support the idea of a common semantic system 
shared by verbal and visual inputs (Vandenberghe, Price, Wise, Josephs, \& Frackowiak, 1996). Vandenberghe et al. presented subjects with item triplets, either words or pictures, and they were required to match the stimuli for (1) meaning (verbal-associative semantic task), (2) for "real-life" size (visual semantic task), or (3) for actual presented size (baseline condition). The authors measured the brain activity associated with the different processing tasks. They found activation in overlapping brain regions during both semantic processing tasks, specifically in the left superior occipital gyrus, middle and inferior temporal cortex, and the inferior frontal gyrus. They did find areas of activation specific to processing of pictures and words, but the activation was not specific to the type of semantic processing required. Thus, the brain areas that were selectively activated for pictures and for words are those dedicated to recognizing pictures and words, respectively, whereas the areas that were activated during semantic processing of pictures and words were shared and overlapping. These results, then, provide at least initial neuroanatomical evidence for a unitary semantic system representing both visual and nonvisual aspects of meaning.

Thus far we have argued that neuropsychological data concerning modality-specific semantic systems do not support separate visual and verbal semantic systems. A second set of results that addresses the issue of the internal structure of the semantic system comes from patients who demonstrate category-specific semantic deficits. We turn now to a review of these results.

\section{Category-Specific Semantic Deficits: \\ The Visual-Functional Knowledge Distinction}

Warrington and Shallice (1984) presented the first well-documented cases of category-specific semantic deficits resulting from brain injury (herpes simplex encephalitis). ${ }^{7}$ Two of these patients (J.B.R. and S.B.Y.) showed deficits in comprehending and naming living things such as animals, fruits, and vegetables in the context of relatively spared ability to comprehend and produce the names of nonliving things such as tools, furniture, and kitchen utensils. For example, S.B.Y. identified or defined $36 / 48(75 \%)$ of nonliving things but no living things, and J.B.R. identified or defined $45 / 48(94 \%)$ of nonliving things and only $2 / 48(4 \%)$ of living things. Further investigation of J.B.R.'s deficit revealed that the distinction between spared and impaired categories was more fine-grained than a living/nonliving one. J.B.R. showed selective problems in comprehending and naming musical instruments, gemstones, metals, fabrics, and foods in addition to animals, fruits, and vegetables. Therefore, the patient's deficits did not appear to respect a categorical principle such as living/nonliving.

A number of studies since then have reported patients showing dissociations in processing between living and nonliving things (Basso, Capitani, \& Laiacona, 1988; Caramazza \& Shelton, 1998; H. Damasio, Grabowski, Tranel, Hichwa, \& Damasio, 1996; DeRenzi \& Lucchelli, 1994;
Farah, Hammond, Mehta, \& Ratcliff, 1989; Farah, McMullen, \& Meyer, 1991; Farah, Meyer, \& McMullen, 1996; Hart \& Gordon, 1992; Hillis \& Caramazza, 1991; Laiacona, Barbarotto, \& Capitani, 1993; Laiacona, Capitani, \& Barbarotto, 1997; Laws, Evans, Hodges, \& McCarthy, 1995; McCarthy \& Warrington, 1988; Pietrini et al., 1988; Powell \& Davidoff, 1995; Sartori \& Job, 1988; Sheridan \& Humphreys, 1993; Silveri \& Gainotti, 1988; Sirigu, Duhamel, \& Poncet, 1991; Warrington \& McCarthy, 1983, 1987). However, several studies also demonstrated that patients may show deficits that are not restricted to just the category of living things (Silveri \& Gainotti, 1988; Warrington \& Shallice, 1984). For example, Silveri and Gainotti (1988) reported a patient who showed a deficit for living things, foods, and musical instruments.

The existence of patients who present with semantic deficits for some categories of knowledge but not others could indicate that conceptual knowledge is organized categorically. This possibility has never really been entertained seriously, however, in part because the reported category-specific deficits have been rather complex and seemed to cut across the living/nonliving divide; for example, the early cases described by Warrington and Shallice showed difficulty with living things but also food and musical instruments. Given the diverse nature of category deficits, Warrington and her colleagues (Warrington \& McCarthy, 1983, 1987; Warrington \& Shallice, 1984) sought to account for their occurrence by proposing that conceptual knowledge is organized into modalityspecific components. In this theory, the principal distinction is between visual and functional properties. ${ }^{8} \mathrm{~A}$ schematic representation depicting the "sensory/functional" theory of semantic organization is presented in Figure $4 .{ }^{9}$ In this case, the modality of information refers to the type of information associated with the object regardless of the input modality or the nature of the response required.

According to this theory, sensory and functional properties are differentially important in identifying members of the living and nonliving categories, with sensory information being much more important for distinguishing among living things and functional information being much more important for distinguishing among nonliving things. Therefore, damage to sensory properties should result in greater impairments to living things, since this information is more important in identifying members of this category. This explanation also supposedly accounts for the somewhat strange association of categories that have been reported to be damaged together, such as animals, foods, and musical instruments, since presumably the items in these categories may all be more dependent on sensory than functional properties for distinguishing among them.

The theory also predicts that patients should be differentially impaired with visual/perceptual knowledge within the impaired categories. Several researchers have claimed to have confirmed this prediction (Basso et al., 1988; DeRenzi \& Lucchelli, 1994; Farah et al., 1989; Sartori \& Job, 1988; Silveri \& Gainotti, 1988). For example, Sil- 


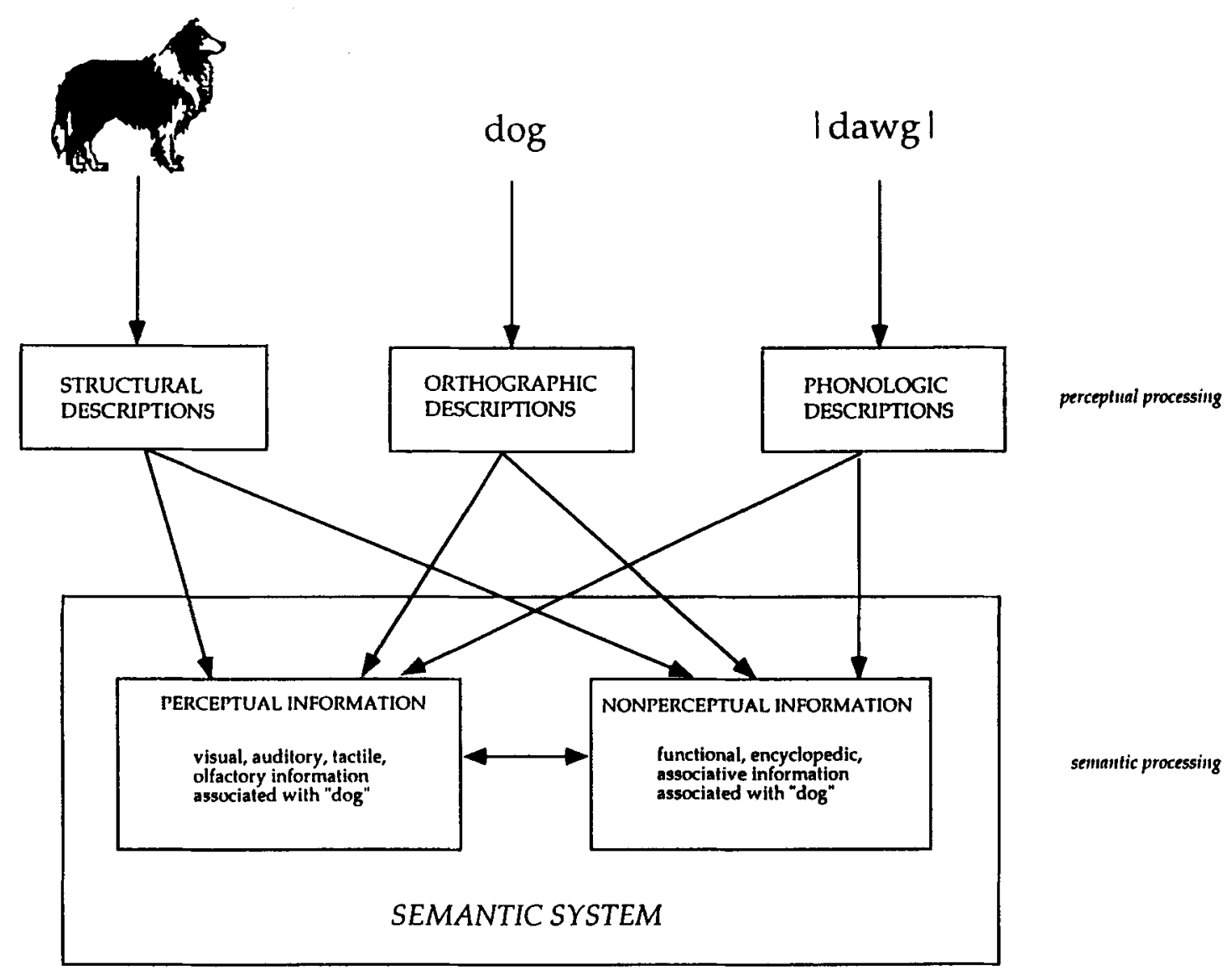

Figure 4. An example of a model postulating separate knowledge-specific semantic systems based on sensory features versus nonsensory features.

veri and Gainotti described a patient (L.A.) who showed a category $\times$ modality interaction effect: The patient was more impaired with living items $(11 / 54=20 \%)$ than with nonliving items $(22 / 28=79 \%)$ and was more impaired with visual $(1 / 11=9 \%)$ than with nonperceptual information associated with living items $(8 / 14=58 \%)$. Thus, the patient's deficit was disproportionately greater for a category of items and a certain type of information associated with those items.

Converging arguments in favor of this account came from a connectionist model developed by Farah and McClelland (1991). In their model, visual and functional properties are represented in two independent but interconnected networks, and the ratio of visual to functional knowledge for living things is larger than that for nonliving things. The actual ratio of visual to functional knowledge for living and nonliving categories was determined by having subjects rate dictionary definitions of items in terms of the number of visual or functional properties associated with each definition. Subjects were given a list of definitions for living and nonliving items and told to circle either information that referred to the visual appearance of the item or information that referred to "what the item does" or "what it is for." From this, Farah and McClelland determined that the ratio of visual information to functional information for living things and nonliving things is $7.7: 1$ and $1.4: 1$, respectively. When Farah and McClelland damaged the visual knowledge network, they found a category-specific deficit for living things. This result rests, of course, on the validity of the initial intuition by Warrington and her colleagues that living things (or certain categories of items) rely more heavily on visual information to distinguish among them, and on the validity of Farah and McClelland's rating data. We return to this point below.

Although the sensory/functional theory has become the received view of category-specific deficits, various observations have undermined the usefulness and validity of this explanation. First, several researchers questioned the validity of category-specific deficits in general, suggesting that the results may have been artifacts of factors such as familiarity, frequency, and/or visual complexity (e.g., Funnell \& Sheridan, 1992; Gaffan \& Heywood, 1993; Stewart, Parkin, \& Hunkin, 1992). For example, Stewart et al. described a patient who showed a categoryspecific effect for animals $(30 / 55=55 \%)$ when tested with materials used by other investigators, but the effect disappeared when they controlled for the factors of famil- 
iarity and visual complexity (animate, $15 / 36=42 \%$; inanimate, $13 / 36=36 \%$ ). Moreover, Stewart et al. demonstrated that normal control subjects were slower to respond to visual information than to functional information associated with animals and found that visual information for animals was less familiar than functional information.

These findings raise several important concerns. They suggest that category-specific deficits may be artifacts of uncontrolled factors rather than true effects. They also suggest that the category $\times$ modality interactions reported previously may well have been effects of category variation in familiarity rather than true interactions. And, the results suggest that the influence of familiarity may be responsible for some of the associations of categories previously reported to be damaged together such as gemstones, fabrics, and musical instruments, categories one would imagine would not be highly familiar to the average person. Thus, those categories may not necessarily be damaged together because of some underlying semantic principle, but because they are all unfamiliar.

The fact that familiarity strongly influences performance could indicate that in some cases the putative category-specific semantic deficits are not dissociations between categories of knowledge but rather dissociations between familiar and less familiar concepts, irrespective of category. However, more recent reports of patients with category-specific deficits have controlled for these factors and the patients still showed category-specific knowledge deficits (e.g., Caramazza \& Shelton, 1998; Farah et al., 1996; Forde, Francis, Riddoch, Rumiati, \& Humphreys, 1997; Gainotti \& Silveri, 1996; Hart \& Gordon, 1992; Laiacona et al., 1993; Laiacona et al., 1997; Lambon-Ralph, Howard, Nightingale, \& Ellis, 1998; Moss, Tyler, Durrant-Peatfield, \& Bunn, 1998; Samson, Pillon, \& De Wilde, 1998; Sheridan \& Humphreys, 1993). Furthermore, there are reports of patients who show selective damage to nonliving items - the easier or more familiar category - suggesting that some of the category effects must be true effects-or at least not simply the result of differences in the familiarity of the items within a category (e.g., Hillis \& Caramazza, 1991; LambonRalph et al., 1998; Sacchett \& Humphreys, 1992; Warrington \& McCarthy, 1983, 1987). However, the lesson to be learned from the critiques by Stewart et al. and Funnell and Sheridan (1992) is an important one: Familiarity has a strong influence on performance and may have accounted for some of the strange categorical associations and for the category $\times$ modality interactions that have been reported for some studies of category-specific deficits. Although this conclusion does not directly undermine the sensory/functional theory, it raises doubt about the validity of various results that have been cited in its support. ${ }^{10}$

However, a number of empirical results are problematic for the sensory/functional theory. First, there are reports of dissociations of performance that are not easily explained by the theory. For example, Hart, Berndt, and Caramazza (1985) reported a patient who was impaired for naming fruits and vegetables $(67 / 107=63 \%)$, but not animals or even other food items $(262 / 269=97 \%)$ (see also Farah \& Wallace, 1992). Caramazza and Shelton (1998) reported a patient who was impaired for animals $(16 / 47=34 \%)$ but not any other living things $(100 \%)$ (or other categories such as musical instruments $[8 / 10=$ $80 \%$ ] or food items [ $100 \%$, which have been found to be associated with living things), and Hillis and Caramazza (1991) reported a patient with selective sparing of animals ( $72 \%-92 \%$ correct) but not fruits and vegetables $(7 \%$ $17 \%$ correct). These patterns of performance are not readily explicable by appeal to the sensory/functional theory; according to this theory, damage to visual properties should result in damage to those items relying most heavily on those properties - presumably the categories of animals, fruits, and vegetables. These reports clearly present a challenge to the theory.

A second set of results also challenges the sensory/ functional theory. Several reports have demonstrated quite convincingly that, when familiarity of an item and/ or familiarity of the knuwledge associated with that item are controlled, patients who show a deficit for living things do not show the predicted category $\times$ modality interaction (Barbarotto, Capitani, Spinnler, \& Trivelli, 1995; Caramazza \& Shelton, 1998; Funnell \& De Mornay Davies, 1997; Laiacona et al., 1993; Laiacona et al., 1997; Sheridan \& Humphreys, 1993). For example, Caramazza and Shelton demonstrated that their patient (E.W.), who had a clear deficit for animals only, was equally impaired on visual $(74 / 100=74 \%)$ and functional knowledge $(115 / 150=77 \%)$ of the items in this semantic category. Moreover, E.W.'s performance was nearly perfect on equally difficult questions concerning visual and functional information for fruit and vegetable items. These results strongly contradict the predictions from the sensory/functional theory.

And finally, although Farah and McClelland (1991) provided putative empirical support for the initial intuition that sensory properties are more important for defining living things than nonperceptual properties, problems with this study may undermine its usefulness for addressing the issues of how knowledge can fractionate to result in category-specific deficits. The results obtained by these authors may simply reflect an artifact of the instructions given to subjects for identifying sensory and nonperceptual features of objects in the living and nonliving categories. Specifically, the instructions given to subjects may have biased them against identifying nonperceptual features for living things. In the attempt to determine the amount of functional information associated with living and nonliving categories, Farah and McClelland asked subjects to underline information showing "what the item does or what it is for" (p. 342). These instructions could have led subjects to exclude a large amount of nonperceptual information that is included in definitions of living things, such as "lives in Africa," "carnivore," "grows underground," "flies," and so on. However, this information is crucial to the definition of living things 
and is the type of information that has been included in the "functional" set of information on which patients have been tested (e.g., Farah et al., 1989). Caramazza and Shelton (1998) replicated this experiment but changed the instructions so that subjects were asked to underline either all sensory properties or all nonsensory properties in the definitions used by Farah and McClelland. They found that the ratios of sensory to nonsensory properties for living and nonliving things were 2.9:2.5 and 2.2:2.3, respectively. Thus, there appears to be little empirical evidence for the initial intuition that living things rely heavily on sensory properties for determining their meaning (see also McRae et al., 1997).

Two other explanations have been offered for the existence of category-specific deficits. One explanation is that category-specific deficits reflect the fact that concepts within a category have many correlated properties in common (see, e.g., Caramazza et al., 1990; McRae et al., 1997; Tyler \& Moss, 1997). For example, the model reviewed in the last section, $\mathrm{OUCH}$, can accommodate the category-specific results by assuming that certain properties of objects are strongly intercorrelated (e.g., the property "having eyes" is strongly correlated with the property "being capable of self-initiated motion"), and members of superordinate categories have many properties in common. If brain damage can selectively affect specific areas of semantic space (because of how this knowledge is distributed in the brain), category-specific deficits can arise. That is, damage to any area populated by properties that are important for the category of living things would result in a category-specific deficit. Although these types of theories can easily account for the emergence of category-specific deficits, they fail to provide an explanation as to why category-specific deficits respect a tripartite distinction of animals, plants, and artifacts and as to why the majority of category-specific deficits demonstrate a deficit to animals or living things in general as opposed to a deficit for artifacts.

A recent proposal that attempts to provide an explanation for these two facts is that the semantic system may have even more internal structure than previously thought and that some semantic category deficits can be interpreted as truly categorical deficits. On this account, knowledge is organized in broad domains that reflect evolutionarily salient distinctions of conceptual knowledge"domain-specific knowledge hypothesis" (Caramazza \&

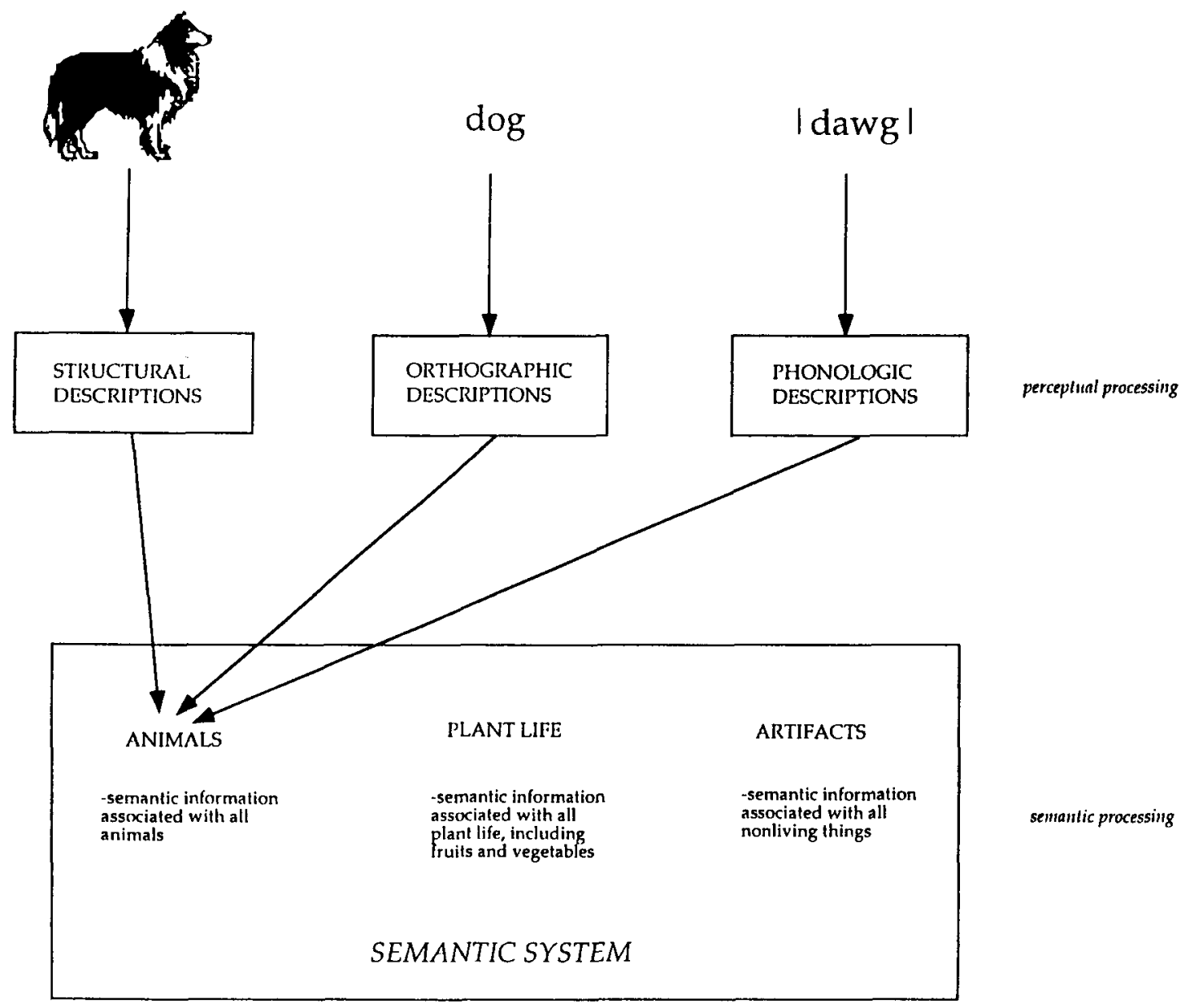

Figure 5. An example of a model postulating a single semantic system organized according to semantic category. 
Shelton, 1998). A schematic representation of this type of model is presented in Figure 5. This model is based on the assumption that evolutionary pressures have led to specific adaptations - highly specialized neural mechanisms - for recognizing animals because of their roles as predators and prey. Similar assumptions could be made for the identification of conspecifics, plant life, and perhaps even for artifacts (see Hauser, 1997, for a discussion concerning the potential value for recognizing "tools" as an evolutionarily important category).

One expectation that follows from this model is that category deficits should be seen only for evolutionarily important categories: humans, animals, and plants (and artifacts, either by contrast to the other categories or because this category has its own specialized neural mechanisms). That is, one should not find finer grained distinctions among category deficits (once familiarity is controlled), and currently, there are no reports of patients who show true categorical deficits for very specific categories (e.g., just vehicles or just land animals or just fruit). Therefore, one testable prediction of this hypothesis is that specific categorical deficits should exist only for those categories that can be shown to have important standing in evolution, and we should not find finer grained category-specific deficits (see also Shelton, Fouch, \& Caramazza, 1998, for discussion of potentially important categories in evolution that expand on this tripartite distinction). Moreover, this hypothesis accounts for the greater number of cases with deficits to animals/living things by assuming that those brain areas dedicated for processing these concepts are highly localized and thus more susceptible to circumscribed damage. It follows, then, that there should always be a greater number of cases with specific impairments to animals/living things, once important factors such as familiarity, age of acquisition, frequency, imageability, and visual complexity have been taken into account.

This hypothesis was proposed as a way to account for the two factors that the other hypotheses could not account for: the consistency in the categories for which dissociations have been reported (animals, plant life, artifacts) and the disparate number of cases with deficits to animals/living things. However, this account leaves open the question of the organization of semantic information within a specific domain. It is not unreasonable to suppose that something along the lines of OUCH (or other correlational accounts) could provide the organizational basis within a semantic domain. In the latter case, it might be possible to find fine-grained category-specific deficits that would reflect the latter organization.

Neuroanatomical evidence suggests that different brain areas are involved in processing the different categories of information (at least comparing animals/living things with nonliving things), although there are conflicting findings about the specific areas and structures that are involved in different semantic domains. There is general agreement that the left temporal lobe is involved in the processing of animals/living things. This is supported by examining the lesion sites of the patients who show category-specific deficits (Gainotti, Silveri, Daniele, \& Giustolisi, 1995) and by examining neuroimaging studies measuring brain activity using PET (H. Damasio et al., 1996; Martin, Wiggs, Ungerleider, \& Haxby, 1996; Perani et al., 1995). However, not all cases with a deficit to these categories have damage to left temporal areas; there have also been reports of category-specific deficits for animals/living things when the damage primarily involved the right temporal lobe (Barbarotto et al., 1995; Laws et al., 1995). And, there are also a few cases of deficits to living things resulting from damage to frontal and inferior parietal areas (Caramazza \& Shelton, 1998; Hillis \& Caramazza, 1991; Laiacona et al., 1993).

Unfortunately, there is even less consistency concerning the processing of nonliving things. A selective deficit to nonliving things has been reported for patients with left frontal and parietal lesions (e.g., Sacchett \& Humphreys, 1992; Warrington \& McCarthy, 1983, 1987) and lesions to the left temporal lobe and basal ganglia (Hillis \& Caramazza, 1991). Thus, damage to the left frontal, parietal, and/or temporal lobes appears to result in deficits to nonliving things. With regard to neuroimaging studies, there is little agreement among them concerning the processing of nonliving things, although they all found evidence of activation in the posterior middle temporal area. In addition, Martin et al.'s (1996) and Perani et al.'s (1995) studies found activation of the frontal lobes for processing of nonliving things.

Although the results from lesion site and neuroimaging studies are not conclusive regarding the relationship of certain brain areas to processing the different semantic categories, evidence is beginning to emerge that distinct areas of the brain are differentially involved in the processing of particular semantic categories. At the very least, it appears that inferior areas of the temporal lobe are important in processing living things, whereas more posterior areas of the temporal lobe and frontoparietal regions are important in processing nonliving things.

\section{Unitary Versus Multiple Semantics: Conclusion}

The study of patients with semantic knowledge deficits provides the opportunity to examine the internal organization of semantic knowledge. The results to date pose an interesting challenge for theories of the organization of meaning: how to account for highly selective deficits to specific domains of knowledge. Some theories of the organization of conceptual knowledge have proposed a modality-based principle - such as the distinction between perceptual and nonperceptual knowledgeto explain category-specific semantic deficits (e.g., Allport, 1985; Paivio, 1971; Shallice, 1988). Alternatively, category- and modality-specific semantic deficits may arise because of principles such as those proposed by OUCH (e.g., the assumption that members of a category share highly correlated semantic properties that can be damaged selectively; Caramazza et al., 1990). In addition, the most intriguing possibility is that conceptual knowledge may be organized into broad domains defined 
by the role these domains may have played in the evolution of the human brain. At the very least, the patterns of performance of patients with semantic deficits, and especially those patients who have deficits to very specific types of knowledge, are highly problematic for modalitybased theories of the organization of conceptual knowledge and point toward a modality-neutral, unitary semantic system that has a great deal of internal structure.

\section{PHONOLOGICAL AND ORTHOGRAPHIC OUTPUT AND GRAMMATICAL CLASS EFFECTS}

Disorders of language production is a well-studied area within cognitive neuropsychology, and the patterns of dissociations that have been observed in this area of research provide useful information for models of normal production. However, because the literature in this area is so vast, we have chosen to focus on topics that reflect the areas in which our interests have been concentrated and that also reflect recent discoveries that have significant implications for models of normal processing. Specifically, we will review evidence on the relationship between phonological and orthographic production to reveal the role of grammatical information in lexical access.

\section{The Independence of Phonological and Orthographic Output Representations}

Traditionally, writing has been viewed as fully dependent on phonological processing, both in the neurological literature (e.g., Geschwind, 1969; Head, 1926; Luria, 1966; Wernicke, 1886/1989) and in the cognitive literature (e.g., Frith, 1980; Hotopf, 1980). The cognitive lit- erature has also typically supported a role of phonology in reading comprehension (e.g., Perfetti \& Bell, 1991; Van Orden, Johnston, \& Hale, 1988), although for present purposes we will concentrate on the evidence concerning the possible role of phonology in production (but see note 14). The evidence we review shows that writing is not dependent on phonological processes. ${ }^{11}$

One type of evidence that has been cited in support of the autonomy of writing processes from phonology is the dissociation of writing and speaking impairments (e.g., Assal, Buttet, \& Jolivet, 1981; Blanken, de Langen, Dittmann, \& Wallesch, 1989; Bub \& Kertesz, 1982; Caramazza, Berndt, \& Basili, 1983; Ellis, Miller, \& Sin, 1983; Hier \& Mohr, 1977; Kremin, 1987; Patterson \& Shewell, 1987). However, these reports did not explore the deficits in enough detail to resolve issues concerning the influence of both sublexical and lexical phonological processing on writing. More recently, detailed evidence has been brought to bear on this issue that has led neuropsychologists to view output phonology and output orthography as independent and dissociable processes (e.g., Hanley \& McDonnell, 1997; Miceli, Benvegnu, Capasso, \& Caramazza, 1997; Rapp, Benzing, \& Caramazza, 1997; Shelton \& Weinrich, 1997), although this viewpoint is not unanimously held (for a review, see Barry, 1994).

Two issues have been addressed in investigations of the independence between speaking and writing processes: (1) the role of sublexical phonological mediation and (2) the role of lexical phonological mediation. The distinction drawn between these two mechanisms of support is that (1) does not rely on stored word forms and instead relies on sublexical phonological-to-orthographic conversion mechanisms whereas (2) relies on the sup-

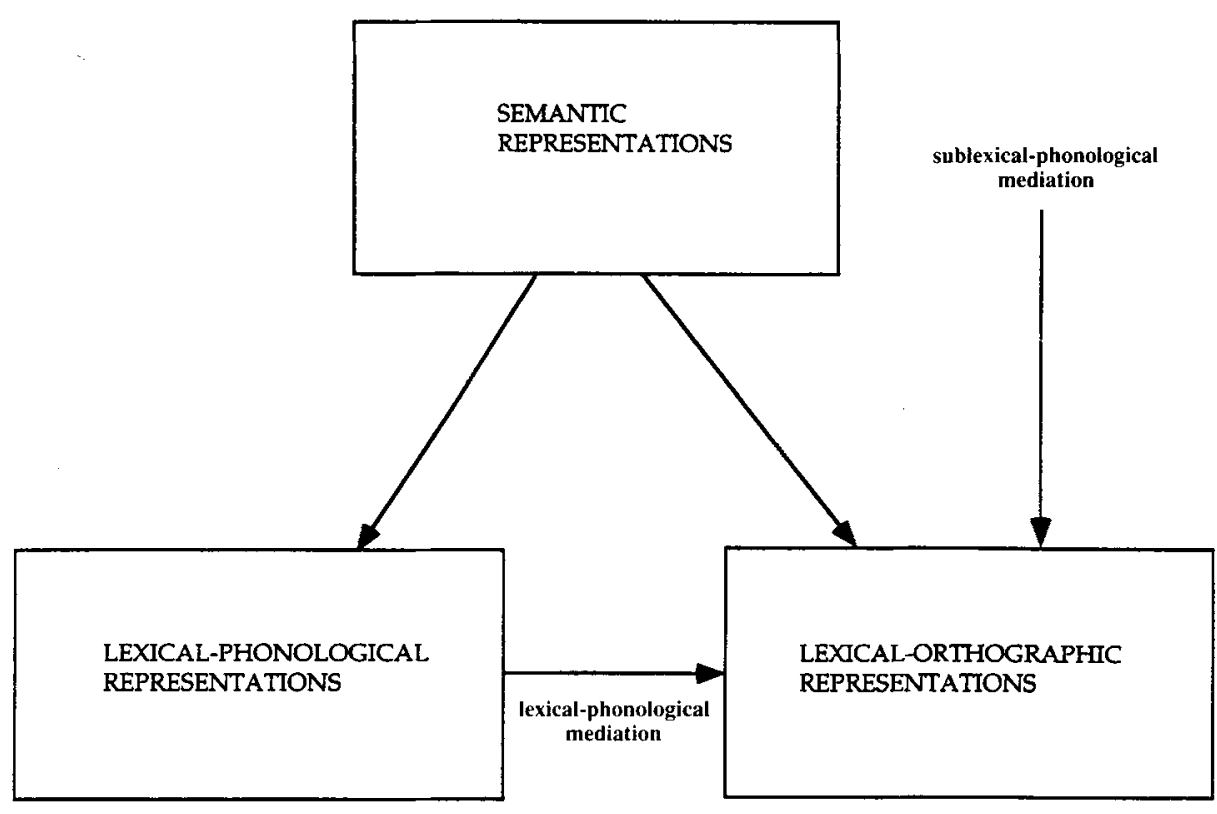

Figure 6. An example of a model postulating an obligatory relationship between phonological support and orthographic output. 


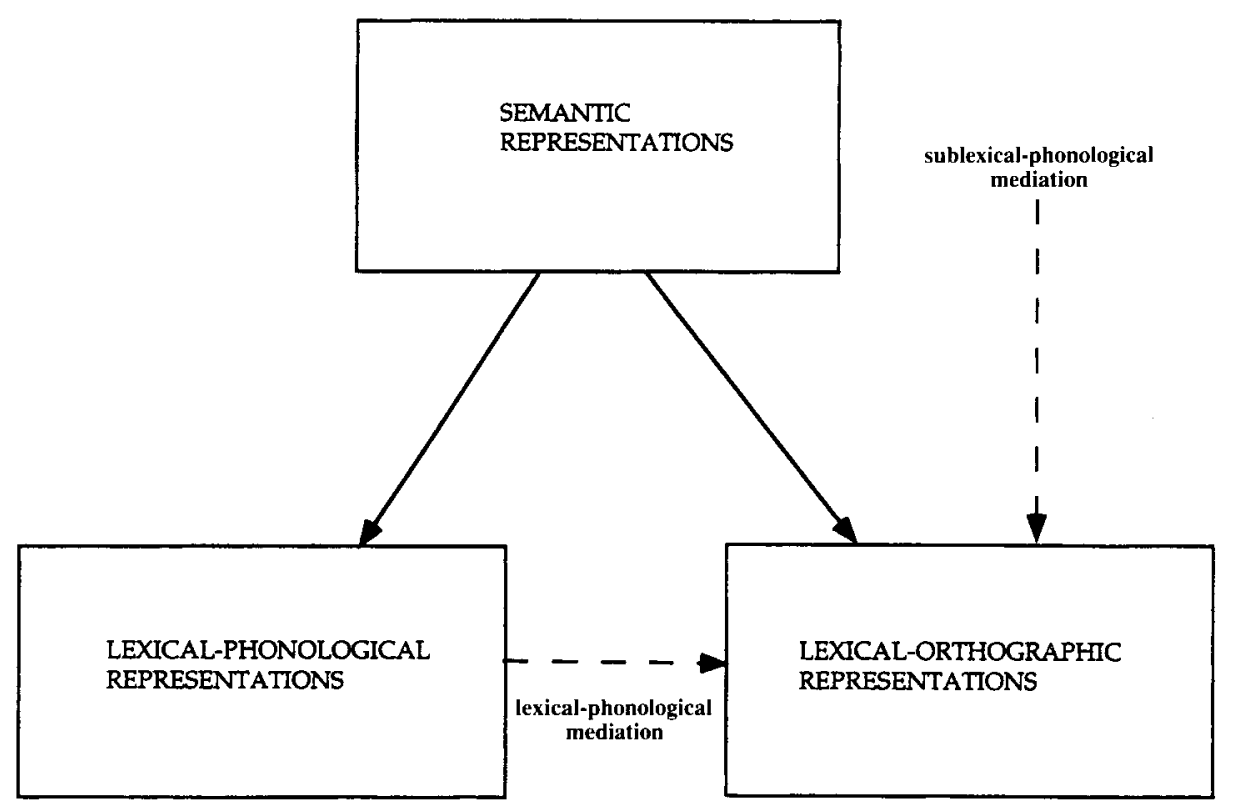

Figure 7. An example of a model postulating a nonobligatory relationship between phonological support and orthographic output.

port of stored word forms. Two models contrasting these positions are shown in Figures 6 and 7. The dashed lines in Figure 7 represent connections that may be established but are not obligatory.

Evidence that sublexical phonological mediation does not play an obligatory role in writing initially came from the performance of patients who could write words successfully despite their inability to write nonwords (e.g., Shallice, 1981). However, since the ability to write nonwords is typically not completely abolished in these patients, there could be some support of sublexical phonology in successful writing (e.g., Barry, 1994; Nolan \& Caramazza, 1983). A recent case reported by Shelton and Weinrich (1997) countered this criticism. Their patient, E.A., was able to successfully write nouns with approximately $85 \%$ accuracy and yet could not write a single nonword $(0 / 75)$. In fact, E.A. correctly produced only $2 / 187(.01)$ individual target graphemes when writing nonwords. Given these results, it is difficult to argue that E.A.'s good performance in writing words reflects partial support from sublexical phonology-to-orthography information since his performance suggested that he had none of this information available to him. Other recent cases have obtained similar results: Successful writing can occur even when there is minimum support from sublexical phonology-to-orthography information (e.g., Hanley \& McDonnell, 1997; Miceli et al., 1997; Rapp et al., 1997).

Thus, there is now clear evidence to support the idea that sublexical phonology-to-orthography conversion mechanisms do not have an obligatory role in writing, but there is still the issue of the role of lexical phonology in writing. Some models of writing assign an obligatory role to stored phonological word forms in writing (Figure 6). However, recent evidence suggests that this role is not necessary and that successful writing can take place independently of all phonological support (Figure 7).

In the case just described, E.A. (Shelton \& Weinrich, 1997) had significant impairments in verbal production, and these were shown to result from damage to phonological output processing rather than semantic processing, articulation, and/or motor programming problems. E.A. demonstrated excellent written picture naming $(228 / 265=.86)$ but severely impaired oral picture naming $(97 / 265=.37)$. The fact that he could write the name of the picture he could not name orally indicates that he could successfully process the picture semantically; the fact that he could successfully repeat the name of the picture he could not spontaneously generate in oral production indicates that he did not have problems with articulation or motor programming; this conclusion is further supported by the fact that E.A. almost never made phonological errors in naming. ${ }^{12}$ Thus, damage to verbal production must be at the level of lexical output processing, indicating that he could not use stored lexicalphonological word forms in a normal manner. Despite this, however, his ability to write the names of pictures was excellent. And the fact that sublexical phonology-toorthography processing was completely damaged in E.A. leads to the conclusion that his ability to write was independent of his ability to use either lexical or sublexical phonology-to-orthography information. Thus, ortho- 
graphic and phonological (output) lexical forms are stored and used separately.

Hanley and McDonnell (1997) presented a patient, P.S., with severely restricted ability to use sublexical phonology-to-orthography conversion mechanisms. P.S. was at chance $(19 / 35=.54)$ in deciding whether or not the names of two pictures rhymed, but could accurately write the names of both pictures. This suggests that he could not access the phonological representations of words he spelled correctly. Another test of his ability to use phonological information to support spelling was a naming-to-definition task for homophones. P.S. was given a definition that fit one of the homophones (e.g., "seven of them in a week") and was asked to write the word being defined (e.g., days) or to write the word that sounded the same as the word being defined (e.g., daze). When he was asked to spell the homophone that matched the definition, he succeeded on all but one trial $(19 / 20=.95)$. When he was given both the definition and the spoken word form (|deiz $\mid)$ and asked to write the word that sounded the same as the one being defined, he very often correctly wrote the nondefined homophone $(17 / 20=$ $.85)$. However, when he was only given the definition and was required to write the nondefined homophone, his performance dropped considerably $(8 / 20=.40)$. Since he could spell the nondefined homophone when given the definition and the spoken word form, his poor performance cannot be attributed either to problems in producing the alternative word or to problems spelling that specific word form. If P.S. was using phonological word forms to support spelling, he should have been equally capable of spelling both forms of the homophone since the identical phonological form would be used to address orthography. Instead, P.S.'s failure to write homophone pairs in conjunction with his chance-level performance on rhyme judgments of words he wrote successfully suggests that he was only able to access orthography directly from semantics without relying on support from stored phonological word forms (or sublexical phonological information).

Another way in which this issue has been addressed has been through the use of a double naming task in which patients are asked to both speak out and write the name of pictured objects. Researchers have presented patients (W.M.A., Miceli et al., 1997; P.W., Rapp et al., 1997) whose naming difficulties could be localized at the level of phonological output and who were unable to use sublexical phoneme-to-grapheme conversion mechanisms to write (as demonstrated by their inability to spell nonwords). The patients were asked to name pictures orally and in writing in the same trial (i.e., the patient was asked to orally name a picture and then immediately write the name or vice versa). Both W.M.A. and P.W. demonstrated inconsistencies in responding between the two modalities, even though the responses were produced immediately one after the other. For example, given the target picture pillow, P.W. said "pillow" and wrote "hed." And, given the target picture peppers, W.M.A. wrote tomato and said "artichoke." Crucially, the inconsistencies were lexical. That is, the patients would either make semantic errors in only one modality of output or would make different semantic errors in the two modalities. The presence of semantic errors, in the absence of a semantic knowledge deficit, indicates that the patients' deficits were in accessing output lexical forms and not in accessing the phonological and/or orthographic information associated with the output. ${ }^{13}$ The production of different lexical responses in the two modalities implies that the written response could not have been determined by its phonological content, for otherwise the same lexical response would have been produced. These results are incompatible with a theory of lexical organization that states that phonological word forms have an obligatory role in written word production.

The studies we have reviewed investigated the issue of the independence between phonological and orthographic output using a variety of techniques with different patients, and the results converge in support of the conclusion that writing can be carried out independently of speaking. The implication to be drawn from these results is not that phonology and orthography do not interact in the normal course of writing but that phonology is not obligatory for successful writing. ${ }^{14.15}$ We can use this conclusion as the basis for addressing more general questions concerning mechanisms involved in lexical accessspecifically, questions about the role of factors, such as grammatical class, in writing and speaking.

\section{Grammatical Class Effects}

An extremely robust and well-studied finding with brain-damaged patients is the influence of grammatical class on production. There are numerous reports demonstrating that some aphasic patients produce nouns much better than either main verbs or function words (e.g., Berndt, Mitchum, Haendiges, \& Sandson, 1997; Caramazza \& Hillis, 1991; A. R. Damasio \& Tranel, 1993; Kohn, Lorch, \& Pearson, 1989; McCarthy \& Warrington, 1985; Miceli, Silveri, Villa, \& Caramazza, 1984; Myerson \& Goodglass, 1972). There are also reports of patients who produce verbs better than nouns (e.g., Baxter \& Warrington, 1985; Berndt et al., 1997; Breedin \& Martin, 1996; Caramazza \& Hillis, 1991; A. R. Damasio \& Tranel, 1993; De Renzi \& di Pellegrino, 1995; Marshall, Chiat, Robson, \& Pring, 1996; Miceli, Silveri, Nocentini, \& Caramazza, 1988; Zingeser \& Berndt, 1988) and patients who produce open-class words (nouns and verbs) much better than closed-class words (e.g., Andreewsky \& Seron, 1975; Caramazza, Berndt, \& Hart, 1981; Gardner \& Zurif, 1975; and papers in Coltheart, Patterson, \& Marshall, 1980). Better production of function words as compared with open-class words was also described in patients with semantic dementia (e.g., Breedin \& Saffran, 1997; see also Schwartz et al., 1979) and jargon aphasia (Buckingham, 1991). 
These patterns of dissociations allow a number of plausible hypotheses about the organization of lexical knowledge, but for the purposes of this review the focus will be on the contrasting patterns of performance between noun and verb production. The fact that nouns are often found to be processed better than verbs following brain damage could merely reflect an abstractness effect-verbs are typically more abstract than nouns, and many patients show more problems processing abstract than concrete nouns (e.g., McCarthy \& Warrington, 1985). However, the existence of patients who perform better with verbs than nouns effectively eliminates this explanation as a general explanation of all selective verb impairments (see, e.g., Berndt et al., 1997, for discussion of this argument). Furthermore, the grammatical class effect is obtained even when the concreteness of test items is controlled (Caramazza \& Hillis, 1991).

In some patients, the differential performance in processing nouns and verbs is most likely the result of a deficit at the lexical-semantic level (i.e., in understanding the meaning of either the nouns or verbs, e.g., Berndt et al., 1997; McCarthy \& Warrington, 1985; Miceli et al., 1988). For these patients, it is not clear whether the selective deficit in processing one class of words - say, nounsis due to their grammatical status - being a noun--or their semantic status-being an object or thing. However, there are reports of patients whose selective deficit in processing nouns or verbs is not due to damage at the semantic level and, thus, allows the inference that the basis for the differential performance is due to the grammatical status of the words.

There is evidence to suggest that the dissociation in performance between different grammatical classes can be a result of damage to output lexical processing and not damage to the semantic system itself (e.g., Caramazza \& Hillis, 1991; Hillis \& Caramazza, 1995b; Rapp \& Caramazza, 1997). Patients H.W. and S.J.D., described by Caramazza and Hillis (1991), are typical of the cases who have been shown to produce differential patterns of performance with nouns and verbs in speaking and writing.

One patient (H.W.) had significantly greater problems with spoken (reading and picture naming; 240/356 = $67 \%$ ) than with written (writing to dictation and picture naming; $100 \%$ ) output. The other patient (S.J.D.) had significant problems with written output $(293 / 356=$ $82 \%)$ and no problems with spoken output $(352 / 356=$ $99 \%$ ). Interestingly, when the patients' performance was examined in spoken and written output for different grammatical classes, H.W. performed significantly worse in spoken production of verbs $(22 \%)$ than nouns $(56 \%)$ and equally well with both grammatical classes in written production $(99 \%)$. S.J.D., on the other hand, performed significantly worse in written production of verbs $(70 \%)$ than nouns $(99 \%)$ and equally well with both grammatical classes in spoken production $(97 \%$ and $99 \%$, respectively). And, importantly, when these 2 patients were tested on homonym production (e.g., noun, the watch; verb, to watch), the same pattern of contrasts was obtained, and in fact for H.W. the difference in performance was more pronounced; he orally produced $46 \%$ of the verbs and $88 \%$ of the nouns but wrote $96 \%$ and $98 \%$, respectively. These findings suggest that the impairments are not the result of particular difficulties in producing specific phonological or orthographic forms, but rather a difficulty associated with access to lexical forms.

Error patterns for the 2 patients also differed across output modalities. H.W. and S.J.D. made semantic errors in only one modality of output (the more impaired modality for each patient). ${ }^{16}$ Both patients' normal performance on tests of comprehension eliminated a lexical-semantic locus for the naming impairment and instead localized the deficit at the level of selection of phonological and orthographic output forms. Moreover, a semantic deficit for a specific grammatical class was ruled out given the normal performance by each patient in the intact production modality (writing for H.W. and speaking for S.J.D.).

These results have important implications for theories of lexical access in production. The fact that verbs were selectively impaired in different modalities in each patient indicates that the deficit was one of activating a specific grammatical category within a modality-specific lexical output component, rather than a modalityindependent lexical output component. Thus, the implication is that lexical output forms are represented independently by modality (this also was supported by the evidence reviewed in the previous section). Furthermore, the results invite the hypothesis that each of the modalityspecific lexical output forms is independently specified for grammatical class. ${ }^{17}$ In other words, we have a tripartite distinction between semantic information, lexical form information (phonological and orthographic), and grammatical information, with each type of information independently specified. The distinction between output forms and grammatical information could be realized in (at least) two ways. Modality-specific lexical output forms may be organized according to grammatical class. On this view, words of different grammatical classes would be represented in different areas of the brain. ${ }^{18}$ Or, the connections between modality-specific output forms and syntactic nodes representing grammatical class could be damaged. On this view, a syntactic node is shared by the two output forms. Damage to the connections from a modality-specific output lexicon would result in a grammatical class deficit for that modality. To date, there are no data to differentiate between these two possibilities. ${ }^{19}$

Additional evidence regarding the independence of lexical output forms and syntactic information comes from studies of patients who can retrieve grammatical information about words they are unable to produce (e.g., Badecker, Miozzo, \& Zanuttini, 1995; Henaff Gonon, Bruckert, \& Michel, 1989; Miozzo \& Caramazza, 1997). For example, Miozzo and colleagues studied an Italian patient, Dante, who showed severe difficulties retrieving phonological output but who seemed to have normal un- 
derstanding of language. This patient was shown to recall correctly gender information (97\%) (a syntactic feature of the language) associated with words he was unable to produce or even guess their initial (53\%) or final sounds $(47 \%)$. Dante could also accurately report the appropriate auxiliary form of verbs he could not produce $(69 / 70=$ $99 \%$ ). This pattern of results suggests that syntactic information is represented independently of lexical output information (i.e., phonological or orthographic word form information). ${ }^{20}$

Neuroanatomical evidence from (1) studies investigating lesion sites in patients with selective deficits in processing either nouns or verbs (see Gainotti et al., 1995, for review), (2) neuroimaging studies (Fiez, Raichle, Balota, Tallal, \& Petersen, 1996; Martin, Haxby, Lalonde, Wiggs, \& Ungerleider, 1995; Petersen, Fox, Posner, Mintun, \& Raichle, 1989; Wise et al., 1991), and (3) evoked potential (EP) studies (Dehaene, 1995; Pulvermuller, Preissl, Lutzenberger, \& Birbaumer, 1997) support the idea that nouns and verbs are represented separately in the brain, although none of these reports distinguishes between semantic and lexical form processing of nouns and verbs.

Gainotti et al. (1995) reviewed the reported cases of patients with selective deficit to either nouns or verbs and found that selective deficits to nouns are associated with lesions in the left temporal lobe and posterior association areas. Selective deficits to verbs are generally associated with lesions in the left anterosuperior portions of the temporal lobe and inferoposterior parts of the left frontal lobe (although there are exceptions, such as, e.g., H.W., discussed above, who had problems orally producing verbs and whose lesion involved only the left parietal area). Nevertheless, there is a general trend of selective problems with verbs being associated with frontal areas, and selective problems with nouns being associated with temporal (and perhaps some temporal-occipital) areas.

Neuroimaging studies using PET also support this general rule. For example, Martin et al. (1995) investigated word generation involving color words and action words. They found that both types of words activated left prefrontal dorsolateral and left posterior parietal areas but that color words activated bilateral fusiform gyri more strongly in the left, and action words activated left posterior and superior temporal gyri and left inferior frontal areas. Basically, their results indicate that temporofrontal lobe areas are involved with action word generation and the posterior temporal areas are involved with color word generation. Other imaging studies have found similar results, demonstrating that prefrontal and temporoparietal areas are activated in verb generation tasks (Fiez et al., 1996; Petersen et al., 1989; Wise et al., 1991).

And finally, event related potentials (ERP) studies have also provided evidence of a neuroanatomical distinction between nouns and verbs. Pulvermuller et al. (1997; see also Dehaene, 1995) investigated processing of nouns whose meanings have a strong visual feature component and verbs whose meanings have a strong motor compo- nent and measured ERPs for these items during a lexical decision task. They found that ERPs to verbs were larger at central brain sites close to motor cortices as compared with ERPs to nouns, which were larger at occipital sites over visual cortices, thus suggesting that nouns and verbs have distinct cortical topographies. Of course, it is possible that the differences in processing arose because of the differences in the visual components between the two types of words, rather than because of a difference in processing the different grammatical word classes. ${ }^{21}$

The results from neuroanatomical/neuroimaging studies of noun and verb processing using different techniques converge on a general principle: Verb processing tends to be associated with left frontal areas and noun processing tends to be associated with left temporal lobe areas. While there are exceptions to this rule, one thing is clear: There are grammatical word class differences in processing that are also established neuroanatomically.

\section{Deficits of Lexical Access: Implications for Our Understanding of Normal Language Processing}

Detailed investigations of phonological and orthographic production disorders have led to intriguing findings regarding the independence of phonological and orthographic output and the role of grammatical information in accessing those phonological and orthographic forms. Although there has been tremendous resistance to the notion that phonological and orthographic output could be represented and processed independently, recent reports strongly support the view that these two types of knowledge are independent and can be accessed autonomously. That is, the careful documentation and examination of the role of phonology in writing in recent case reports strongly supports the position of lexicalorthographic autonomy.

In addition, recent reports provide convincing evidence that favors the idea that grammatical information can be accessed and processed at the lexical output level for both phonological and orthographic forms, and recent case reports also support the idea that there is independence between the representation and processing of syntactic and semantic information. Taken together, the findings reviewed in this section support a theory of lexical organization in which semantic, syntactic, and lexical form information are represented autonomously both functionally and neuroanatomically.

One important implication from these findings concerns the structure of speech production models. The results we have reviewed allow a very strong inference about the structure of lexical access: Semantic information independently activates phonological and orthographic lexical forms, which are specified for grammatical class. This conclusion is supported by two observations: (1) the fact that words of one grammatical class can be damaged selectively in only one output modality, and (2) the fact that the patients who show these dissociations make semantic errors in only one output modality. These two facts 
together imply that the damage must concern a postsemantic stage of processing (semantics is intact in comprehension and in one output modality) but it must be a stage of processing prior to segmental selection since errors involved lexical and not segmental substitutions. The only possible stage left is the stage where lexical forms are selected. And since the damage is selective for an output modality, the impairment must concern a modalityspecific lexical form.

The evidence from neuropsychology is problematic for theories of lexical access (e.g., Bock \& Levelt, 1994; Dell, 1988, 1990; Dell, Schwartz, Martin, Saffran, \& Gagnon, 1997; Garrett, 1980; Roelofs, 1992) that distinguish between a level of representation where modalityneutral lexical forms associated with syntactic features are specified (lemma level) and a level where modalityspecific lexical nodes are specified (lexeme level). ${ }^{22}$ For on these theories, damage at the level of lemma, where grammatical class is specified, should result in qualitatively similar impairments in speaking and writing. And damage at the level of modality-specific forms should not result in selective impairments for words of one grammatical class. Thus, these theories fail to account for the patterns of selective impairments for grammatical class by modality (see Caramazza, 1997, for discussion).

\section{CONCLUSIONS}

This review has examined cognitive neuropsychological results specifically in relation to issues of semantic and lexical processing and demonstrated that these results place important constraints on models of normal language processing. The structure of semantic knowledge has long been of interest in cognitive psychology, and the results from patients who present with semantic processing deficits have provided us with important clues regarding the nature of this structure. It would seem that neuropsychological results are best interpreted within a model of semantics that is highly structured and potentially organized according to several biologically salient categories.

The mechanisms involved in lexical access have also been of considerable interest to cognitive scientists. The results from patients who demonstrate differential effects of grammatical class in production and especially the comparison in production between writing and speaking have provided us with intriguing possibilities concerning the mechanisms involved in production. These data place severe constraints on current models of speech production and ultimately require a rethinking of the number and type of levels of representation needed in language production models.

Patient data not only provide us with a unique opportunity to study the effect of highly selective factors on performance but also contribute to our understanding of the relationship between language processing and brain mechanisms. The selective deficits in performance resulting from damage restricted to specific brain areas converge with results from neuroimaging studies. Increasingly, it seems that a highly organized language processing system corresponds to highly organized and specialized neural processing mechanisms.

\section{REFERENCES}

Allport, D. A. (1984). Speech production and comprehension: One lexicon or two? In W. Prinz \& A. F. Sanders (Eds.), Cognition and motor processes (pp. 209-228). Berlin: Springer.

AllPORT, D. A. (1985). Distributed memory, modular subsystems and dysphasia. In S. K. Newman \& R. Epstein (Eds.), Current perspectives in dysphasia (pp. 207-244). Edinburgh: Churchill Livingstone.

ANDREEWSKY, E., \& SERON, X. (1975). Implicit processing of grammatical rules in a classical case of agrammatism. Cortex, 11, 379-390.

Assal, G., Buttet, J., \& Jolivet, R. (1981). Dissociations in aphasia: A case report. Brain \& Language, 13, 223-240.

Badecker, W., Miozzo, M., \& Zanuttini, R. (1995). The two-stage model of lexical retrieval: Evidence from a case of anomia with selective preservation of grammatical gender. Cognition, 57, 193-216.

Barbarotto, R., Capitani, E., Spinnler, H., \& Trivelli,, C. (1995). Slowly progressive semantic impairment with category specificity. Neurocase, 1, 107-119.

BARRY, C. (1994). Spelling routes (or roots or rutes). In G. D. A. Brown \& N. C. Ellis (Eds.), Handbook of spelling: Theory, process and intervention (pp. 27-49). New York: Wiley.

Basso, A., Capitani, E., \& Laiacona, M. (1988). Progressive language impairment without dementia: A case with isolated category specific semantic defect. Journal of Neurology, Neurosurgery, \& Psychiatry, 51, 1201-1207

Baxter, D. M., \& Warrington, E. K. (1985). Category-specific phonological dysgraphia. Neuropsychologia, 23, 653-666.

BeAuvois, M.-F. (1982). Optic aphasia: A process of interaction between vision and language. Philosophical Transactions of the Royal Society of London: Series B, 298, 35-47.

Beauvois, M.-F., Saillant, B., Meininger, V., \& Lhermitte, F. (1978). Bilateral tactile aphasia: A tacto-verbal dysfunction. Brain, 101, 381-401.

BERNDT, R. S. (1991). Sentence processing in aphasia. In M. T. Sarno (Ed.), Acquired aphasia (2nd ed., pp. 223-270). New York: Academic Press.

Berndt, R. S., Mitchum, C. C., \& Haendiges, A. N. (1996). Comprehension of reversible sentences in agrammatism: A meta-analysis. Cognition, 58, 289-308.

Berndt, R. S., Mitchum, C. C., Haendiges, A. N., \& Sandson, J (1997). Verb retrieval in aphasia: 1. Characterizing single word impairments. Brain \& Language, 56, 68-106.

Blanken, G., De Langen, E. G., Dittmann, J., \& Wallesch, C. W. (1989). Implications of preserved written language abilities for the functional basis of speech automatisms (recurring utterances): A single case study. Cognitive Neuropsychology, 6, 211-249.

BocK, J. K., \& LEVELT, W. J. M. (1994). Language production: Grammatical encoding. In M. A. Gernsbacher (Ed.), Handbook of psycholinguistics (pp. 945-984). San Diego: Academic Press.

Breedin, S. D. \& Martin, R. C. (1996). Patterns of verb impairment in aphasia: An analysis of four cases. Cognitive Neuropsychology, 13, $51-91$.

Breedin, S. D., \& Saffran, E. M. (1997). Sentence processing in the face of semantic loss: A case study. Unpublished manuscript.

BUB, D., \& KERTESZ, A. (1982). Evidence of lexicographic processing in a patient with preserved written over oral single word naming. Brain, 105, 697-717.

Buckingham, H. W. (1991). Explanations for the concept of apraxia of speech. In M. T. Sarno (Ed.), Acquired aphasia (2nd ed., pp. 271312). San Diego: Academic Press. 
Caramazza, A. (1986). On drawing inferences about the structure of normal cognitive systems from the analysis of patterns of impaired performance: The case for single patient studies. Brain \& Cognition, 5. $41-66$.

CARAmazza, A. (1997). How many levels of processing are there in lexical access? Cognitive Neuropsychology, 14, 177-208.

Caramazza, A., \& Berndt, R. S. (1978). Semantic and syntactic processes in aphasia: A review of the literature. Psychological Bulletin, 85, 898-918.

Caramazza, A., Berndt, R. S., \& Basili, A. G. (1983). The selective impairment of phonological processing: A case study. Brain \& Language, 18, 128-174.

Caramazza, A., Berndt, R. S., \& Hart, J. (1981). "Agrammatic" reading. In F. J. Pirozzolo \& M. C. Wittrock (Eds.), Neuropsychological and cognitive processing in reading (pp. 297-317). New York: Academic Press.

Caramazza, A., \& Hillis, A. E. (1991). Lexical organization of nouns and verbs in the brain. Nature, 349, 788-790.

Caramazza, A., Hillis, A. E., Rapp, B., \& Romani, C. (1990). Multiple semantics or multiple confusions? Cognitive Neuropsychology, 7, $161-190$.

Caramazza, A., \& Miozzo, M. (1997). The relation between syntactic and phonological knowledge in lexical access: Evidence from the "tip-of-the-tongue" phenomenon. Cognition, 64, 309-343.

Caramazza, A., \& Miozzo, M. (1998). More is not always better: A response to Roelofs, Meyer, and Levelt. Cognition, 89, 231-241.

Caramazza, A., \& Shelton, J. R. (1998). Domain specific knowledge systems in the brain: The animate-inanimate distinction. Journal of Cognitive Neuroscience, 10, 1-34.

CaramazZa, A., \& Zurif, E. B. (1976). Dissociation of algorithmic and heuristic processes in language comprehension. Brain \& Language, 3, 572-582.

Coltheart, M., \& Coltheart, V. (1997). Reading comprehension is not exclusively reliant upon phonological representation. Cognitive Neuropsychology, 14, 167-176.

Coltheart, M., Curtis, B., Atkins, P., \& Haller, M. (1993). Models of reading aloud: Dual-route and parallel-distributed-processing approaches. Psychological Review, 100, 589-608.

Coltheart, M., Patterson, K., \& Marshall, J. (1980). Deep dyslexia (2nd ed.). London: Routledge \& Kegan Paul.

Coslett, H. B., \& SafFran, E. M. (1989). Preserved object recognition and reading comprehension in optic aphasia. Brain, 112, 1091-1110.

Coslett, H. B., \& SaFfran, E. M. (1992). Optic aphasia and the right hemisphere: A replication and extension. Brain \& Language, $\mathbf{4 3}$, 148-161.

Damasio, A. R. (1990). Category-related recognition defects as a clue to the neural substrates of knowledge. Trends in the Neurosciences, 13, 95-98.

Damasio, A. R., \& Tranel, D. (1993). Nouns and verbs are retrieved with differently distributed neural systems. Proceedings of the National Academy of Sciences of the United States of America, 90, 4957-4960.

Damasio, H., Grabowski, T. J., Tranel, D., Hichwa, R. D., \& Damasio, A. R. (1996). A neural basis for lexical retrieval. Nature, 380, 499-505.

DEHAENE, S. (1995). Electrophysiological evidence for category-specific word processing in the normal human brain. NeuroReport, 6, 21532157.

DELL, G. S. (1988). The retrieval of phonological forms in production: Test of predictions from a connectionist model. Journal of Memory \& Language, 27, 124-142.

DELL, G. S. (1990). Effects of frequency and vocabulary type on phonological speech errors. Language \& Cognitive Processes, 4, 313-349.

Dell, G. S., Schwartz, M. F., Martin, N., Saffran., E. M., \& GaGNON, D. A. (1997). Lexical access in aphasic and nonaphasic speakers. Psvchological Review, 104, 801-838.

Denes, G., \& Semenza, C. (1975). Auditory modality-specific anomia: Evidence from a case of pure word deafness. Cortex, 11, 401-411.

DeRenzi, E., \& Lucchelli, F. (1994). Are semantic systems separately represented in the brain? The case of living category impairment. Cortex, 30, 3-25.
Derenzi, E., \& di Pellegrino, G. (1995). Sparing of verbs and preserved but ineffectual reading in a patient with impaired word production. Cortex, 31, 619-636.

ELlis, A. W. (1984). Introduction to Bramwell's (1897) case of word meaning deafness. Cognitive Neuropsychology, 1, 245-258

Ellis, A. W., Miller, D., \& Sin, G. (1983). Wernicke's aphasia and normal language processing: A case study in cognitive neuropsychology. Cognition, 15, 111-144.

Farah, M. J., Hammond, K. M., Mehta, Z., \& Ratcliff, G. (1989). Category-specificity and modality-specificity in semantic memory. Neuropsychologia, 27, 193-200.

Farah, M. J., \& MCClelland, J. L. (1991). A computational model of semantic memory impairment: Modality specificity and emergent category specificity. Journal of Experimental Psychology: General, 120, 339-357.

Farah, M. J., McMullen, P. A., \& Meyer, M. M. (1991). Can recognition of living things be selectively impaired? Neuropsychologia, 29, 185-193.

Farah, M. J., Meyer, M. M., \& McMullen, P. A. (1996). The living/ nonliving dissociation is not an artifact: Giving an a priori implausible hypothesis a strong test. Cognitive Neuropsychology, 13, 137-154.

Farah, M. J., \& Wallace, M. A. (1992). Semantically-bounded anomia: Implications for the neural implementation of naming. Neuropsychologia, 30, 609-621.

Fiez, J. A., Raichle, M. E., Balota, D. A., Tallal, P., \& Petersen, S. E. (1996). PET activation of posterior temporal regions during auditory word presentation and verb generation. Cerebral Cortex, 6, 1-10.

Forde, E. M. E., Francis, D., Riddoch, M. J., Rumiati, R. I., \& Humphreys, G. W. (1997). On the links between visual knowledge and naming: A single case study of a patient with a category-specific impairment for living things. Cognitive Neuropsychology, 14, 403458.

Franklin, S., Howard, D., \& Patterson, K. (1994). Abstract word meaning deafness. Cognitive Neuropsychology, 11, 1-34.

FrITH, U. (1980). Unexpected spelling problems. In U. Frith (Ed.), Cognitive processes in spelling (pp. 495-515). London: Academic Press.

FunNell, E., \& DE Mornay Davies, P. (1997). JBR: A reassessment of concept familiarity and a category-specific disorder for living things. Neurocase, 9, 135-153.

Funnell, E., \& Sheridan, J. S. (1992). Categories of knowledge? Unfamiliar aspects of living and nonliving things. Cognitive Neuropsychology, 9, 135-153.

Gaffan, D., \& Heywood, C. A. (1993). A spurious category-specific visual agnosia for living things in normal humans and nonhuman primates. Journal of Cognitive Neurosciences, 5, $118-128$.

Gainotti, G., \& Silveri, M. C. (1996). Cognitive and anatomical locus of lesion in a patient with a category-specific semantic impairment for living beings. Cognitive Neuropsychology, 13, 357-389

Gainotti, G., Silveri, M. C., Daniele, A., \& Giustolisi, L. (1995). Neuroanatomical correlates of category-specific semantic disorders: A critical survey. In R. A. McCarthy (Ed.), Semantic knowledge and semantic representations. Memory (Vol. 3, Issues $3 \& 4$, pp. 247 264). Hove, England: Erlbaum, Taylor \& Francis.

Gardner, H., \& Zurif, E. (1975). Bee, but not be: Oral reading of $\sin$ gle words in aphasia and alexia. Neuropsychologia, 27, 193-200.

GaRRETT, M. F. (1980). Levels of processing in sentence production. In B. Butterworth (Ed.), Language production (pp. 177-220). New York: Academic Press.

GESCHWIND, N. (1969). Problems in the anatomical understanding of aphasia. In A. L. Benton (Ed.), Contributions of clinical neuropsychology (p. 107). Chicago: University of Chicago Press.

HANLEY, J. R., \& MCDONNELL, V. (1997). Are reading and spelling phonologically mediated? Evidence from a patient with a speech production impairment. Cognitive Neuropsychology, 14, 3-34.

Hakt, J., Bernid, R. S., \& CaRamazza, A. C. (1985). Category-specific naming deficit following cerebral infarction. Nature, 316, 439-440.

HART, J., \& GORDON, B. (1992). Neural subsystems for object knowledge. Nature, 359, 60-64.

HAUSER, M. (1997). Artifactual kinds and functional design features: What a primate understands without language. Cognition, 64, 285-308. 
HEAD, H. (1926). Aphasia and kindred disorders of speech. London: Cambridge University Press.

Henaff Gonon, M., Bruckert, R., \& Michel, F. (1989). Lexicalization in an anomic patient. Neuropsychologia, 27, 391-407.

HIER, D. B., \& MOHR, J. P. (1977). Incongnuous oral and written naming: Evidence for a subdivision of the syndrome Wernicke's aphasia. Brain \& Language, 4, 115-126.

Hillis, A. E., \& Caramazza, A. (1991). Category-specific naming and comprehension impairment: A double dissociation. Brain, 114, 20812094.

Hillis, A. E., \& Caramazza, A. (1995a). Cognitive and neural mechanisms underlying visual and semantic processing: Implications from "optic aphasia." Journal of Cognitive Neuroscience, 7, 457-478.

Hillis, A. E., \& Caramazza, A. (1995b). Representation of grammatical categories of words in the brain. Journal of Cognitive Neuroscience, 7, 396-407.

Hillis, A. E., Rapp, B., Romani, C., \& Caramazza, A. (1990). Selective impairments of semantics in lexical processing. Cognitive Neuropsychology, 7, 191-243.

Hotopf, N. (1980). Slips of the pen. In U. Frith (Ed.), Cognitive processes in spelling (pp. 287-309). London: Academic Press.

Howard, D., \& FrankLin, S. (1987). Three ways for understanding written words and their use in two contrasting cases of surface dyslexia. In D. A. Allport, D. MacKay, W. Prinz, \& E. Scheerer (Eds.), Language perception and production: Common processes in listening, speaking, reading and writing (pp. 340-366). London: Academic Press.

Howard, D., \& FRANkLIN, S. (1988). Missing the meaning? A cognitive neuropsychological study of the processing of words by an aphasic patient. Cambridge, MA: MIT Press.

Humphreys, G. W., \& RidDoch, M. J. (1988). On the case for multiple semantic systems: A reply to Shallice. Cognitive Neuropsychology, $5,143-150$

Kohn, S. E., \& Friedman, R. (1986). Word meaning deafness: A phonological-semantic dissociation. Cognitive Neuropsychology, $\mathbf{3}$, 291-308.

Kohn, S. E., Lorch, M. P., \& Pearson, D. M. (1989). Verb finding in aphasia. Cortex, 25, 57-69.

KREMIN, H. (1987). Is there more than ah-oh-oh? Alternative strategies for writing and repeating lexically. In M. Coltheart, G. Sartor, \& $\mathrm{R}$. Job (Eds.), The cognitive neuropsychology of language (pp. 295 336). London: Erlbaum.

laiacona, M., Barbarotto, R., \& Capitani, E. (1993). Perceptual and associative knowledge in category specific impairment of semantic memory: A study of two cases. Cortex, 29, 727-740.

Laiacona, M., Capitani, E., \& Barbarotto, R. (1997). Semantic category dissociations: A longitudinal study of two cases. Cortex, 33, 441-461.

Lambon-Ralph, M. A., Howard, D., Nightingale, G., \& Ellis, A. (1998). Are living and nonliving category-specific deficits causally linked to impaired perceptual or associative knowledge? Evidence from a category-specific double dissociation. Neurocase, 4, 311-338.

Laws, K. R., Evans, J. J., Hodges, J. R., McCarthy, R. A. (1995) Naming without knowing and appearance without awareness: Evidence for constructive processes in semantic memory? Memory, $\mathbf{3}$, 409-433.

LEVELT, W. J. M. (1989). Speaking: From intention to articulation. Cambridge, MA: MIT Press.

Lhermitte, F., \& Beauvors, M.-F. (1973). A visual-speech disconnexion syndrome: Report of a case with optic-aphasia, agnosic alexia and colour agnosia. Brain, 96, 695-714.

LURIA, A. R. (1966). Higher cortical functions in man. New York: Basic Books.

Marshall, J., Chiat, S. Robson, J., \& Pring, T. (1996). Calling a salad a federation: An investigation of semantic jargon. Part 2-Verbs. Journal of Neurolinguistics, 9, 251-260.

Martin, A., Haxby, J. V., Lalonde, F. M., Wiggs, C. L., \& UngerLEIDER, L. G. (1995). Discrete cortical regions associated with knowledge of color and knowledge of action. Science, 270, 102-105.

Martin, A., Wiggs, C. L., Ungerleider, L. G., \& Haxby, J. V. ( I996).
Neural correlates of category-specific knowledge. Nature, $\mathbf{3 7 9}$ 649-652.

MCCARThy, R. A., \& WarRington, E. K. (1985). Category specificity in an agrammatic patient: The relative impairment of verb retrieval and comprehension. Neuropsychologia, 23, 709-723.

MCCARTHY, R. A., \& WARRINGTON, E. K. (1988). Evidence for modalityspecific meaning systems in the brain. Nature, 334, 428-430.

MCCARTHY, R. A., \& WARRINGTON, E. K. (1990). Cognitive neuropsychology: A clinical introduction. San Diego: Academic Press.

McRae, K., DE SA, V. R., \& Seidenberg, M. S. (1997). On the nature and scope of featural representations for word meaning. Journal of Experimental Psychology: General, 126, 99-130.

Miceli, G., Benvegnu, B., Capasso, R., \& Caramazza, A. (1997). The independence of phonological and orthographic forms: Evidence from aphasia. Cognitive Neuropsychology, 14, 35-70.

Miceli, G., Silveri, M. C., Nocentini, U., \& Caramazza, A. (1988) Patterns of dissociation in comprehension and production of nouns and verbs. Aphasiology, 2, 351-358.

Miceli, G., Silveri, M. C., Villa, G., \& Caramazza, A. (1984). On the basis for agrammatics difficulty in producing main verbs. Cortex, 20, 207-220.

Mrozzo, M., \& CARAmazza, A. (1997). On knowing the auxiliary of a verb that cannot be named: Evidence for the independence of grammatical and phonological aspects of lexical knowledge. Journal of Cognitive Neuroscience, 9. 160-166.

MONSELL, S. (1987). On the relation between input and output pathways for speech. In D. A. Allport, D. G. MacKay, W. Prinz, \& E. Scheerer (Eds.), Language perception and production relationships between speaking, reading and writing (pp. 273-311). London: Erlbaum.

MORTON, J. (1981). The status of information processing models of language. Philosophical transactions of the Royal Society of London, 295, 387-396.

Moss, H. E., Tyler, L. K., Duranin-Peatfield, M., \& Bunn, E. M. (1998). Two eyes of a see-through: Impaired and intact semantic knowledge in a case of selective deficit for living things. Neurocase, 4, 291-310.

MYerson, R., \& GoOdglass, H. (1972). Transformational grammars of three agrammatic patients. Language \& Speech, 15, 40-50.

NiCKELS, L., \& HowARD, D. (1994). A frequent occurrence? Factors affecting the production of semantic errors in aphasic naming. Cognitive Neuropsychology, 11, 289-320.

Nolan, K. A., \& Caramazza, A. (1983). An analysis of writing in a case of deep dyslexia. Brain \& Language, 20, 305-328.

Pajvio, A. (1971). Imagery and verbal processes. London: Holt, Rinehart \& Winston.

Patterson, K. E., Marshall, J. C., \& Coltheart, M. (1985). Surface dyslexia: Neuropsychological and cognitive studies of phonological reading. London: Erlbaum.

Patterson, K. E., SeidenberG, M. S., \& McClelland, J. L. (1989). Connections and disconnections: Acquired dyslexia in a computational model of reading processes. In R. G. M. Morris (Ed.), Parallel distributed processing: Implications for psychology and neuroscience (pp. 131-181). Oxford: Oxford University Press.

Patterson, K. E., \& Shewell, C. (1987). Speak and spell: Dissociations and word class effects. In M. Coltheart, G. Sartori, \& R. Job (Eds.), The cognitive neuropsychology of language (pp. 273-294). London: Erlbaum.

Perani, D., Cappa, S. F., Bettinardi, V., Bressi, S., Gorno-Tempini, M., Matarrese, M., \& Fazio, F. (1995). Different neural systems for the recognition of animals and man-made tools. NeuroReport, 6 , 1637-1641.

Perfetti, D., \& Belx, L. (1991). Phonemic activation during the first forty milliseconds of word identification: Evidence from backward masked priming. Journal of Memory \& Language, 30, 473-485.

Petersen, S., Fox, P., Posner, M., Mintun, M., \& Raichle, M. (1989). Positron emission tomography studies of the processing of single words. Journal of Cognitive Neuroscience, 1, 153-170.

Pietrini, V., Nertempi, P., Vaglia, A., Revello, M. G., Pinna, V., \& Ferro-MiLone, F. (1988). Recovery from herpes simplex encephalitis: Selective impairment of specific semantic categories with neuro- 
radiological correlation. Journal of Neurology, Neurosurgery, \& Psychiatry, 51, 1284-1293.

Plaut, D. C., McClelland, J. L., Seidenberg, M. S., \& PatterSON, K. (1996). Understanding normal and impaired word reading: Computational principles in quasi-regular domains. Psychological Review, 103, 56-115.

Powell, J., \& DAVIDOFF, J. (1995). Selective impairments of objects knowledge in a case of acquired cortical blindness. Memory, 3,435 . 461.

Pulvermuller, F. (1995). Agrammatism: Behavioral description and neurobiological explanation. Journal of Cognitive Neuroscience, 7 , 165-181.

Pulvermuller, F., Preissl, H., Lutzenberger, W., \& Birbaumer, N. (1997). Nouns and verbs in the intact brain: Behavioral and electrocortical evidence. Unpublished manuscript.

Rapp, B. [C.], Benzing, L., \& Caramazza, A. (1997). The autonomy of lexical orthography. Cognitive Neuropsychology, 14, 71-104.

RAPP, B. [C.], \& CARAMAZZA, A. (1997). The modality-specific organization of grammatical categories: Evidence from impaired spoken and written sentence production. Brain \& Language, 56, 248-286.

Rapp, B. C., Hillis, A. E., \& Caramazza, A. (1993). The role of representations in cognitive theory: More on multiple semantics and the agnosias. Cognitive Neuropsychology, 10, 235-249.

RiDDoch, M. J., \& HumphreYs, G. W. (1987). Visual object processing in optic aphasia: A case of semantic access agnosia. Cognitive Neuropsychology, 4, 131-185.

RidDoch, M. J., Humphreys, G. W., Coltheart, M., \& Funnell, E. (1988). Semantic system or systems? Neuropsychological evidence re-examined. Cognitive Neuropsychology, 5, 3-26.

RoEloFs, A. (1992). A spreading-activation theory of lemma retrieval in speaking. Cognition, 42, 107-142.

Sacchett, C., \& Humphreys, G. W. (1992). Calling a squirrel a squirrel but a canoe a wigwam: A category-specific deficit for artefactual objects and body parts. Cognitive Neuropsychology, 9, 73-86.

Saffran, E. M., \& SchwarTZ, M. F. (1994). Of cabbages and things: Semantic memory from a neuropsychological perspective $-A$ tutorial review. In C. Umiltà \& M. Moscovitch (Eds.), Attention and Performance XV: Conscious and nonconscious information processing (pp. 507-536). Cambridge, MA: MIT Press, Bradford Books.

Samson, D., Pillon, A., \& DE Wilde, V. (1998). Impaired knowledge of visual and nonvisual attributes in a patient with a semantic impairment for living entities: A case of a true category-specific deficit. Neurocase, 4, 273-290.

SARTORI, S., \& JoB, R. (1988). The oyster with four legs: A neuropsychological study on the interaction of visual and semantic information. Cognitive Neuropsychology, 5, 105-132

Schwartz, M. F., Marin, O. S. M., \& Saffran, E. M. (1979). Dissociation of language function in dementia: A case study. Brain \& Language, 7, 277-306.

Schwartz, M. F., Saffran, E. M., \& Marin, O. S. M. (1980). The word order problem in agrammatism: 1. Comprehension. Brain \& Language, 10, 249-262.

Seymour, P. H. K. (1979). Human visual cognition. London: Collier Macmillan.

Shallice, T. (1981). Phonological agraphia and the lexical route in writing. Brain, 104, 413-429.

Shallice, T. (1987). Impairments of semantic processing: Multiple dissociations. In M. Coltheart, G. Sartori, \& R. Job (Eds.), The cognitive neuropsychology of language (pp. 111-127). London: Erlbaum.

SHALLICE, T. (1988). From neuropsychology to mental structure. Cambridge: Cambridge University Press.

Shaldice, T. (1993). Multiple semantics: Whose confusions? Cognitive Neuropsychology, 10, 251-262.

Shelton, J. R., Fouch, E., \& Caramazza, A. (1998). The selective sparing of body part knowledge: A case study. Neurocase, 4, 339-351.

Shelton, J. R., \& Weinrich, M. (1997). Further evidence of a dissociation between output phonological and orthographic lexicons: $\mathrm{A}$ case study. Cognitive Neuropsychology, 14, 105-130.

Sheridan, J., \& Humphreys, G. W. (1993). A verbal-semantic categoryspecific recognition impairment. Cognitive Neuropsychology, 10 143-184.
Silveri, M. C., \& GainotTi, G. (1988). Interaction between vision and language in category-specific impairment. Cognitive Neuropsychology, 5, 677-709.

Sirigu, A., Duhamel, J. R., \& Poncet, M. (1991). The role of sensorimotor experience in object recognition: A case of multimodal agnosia. Brain, 114, 2555-2573.

SNOdGRass, J. G. (1984). Concepts and their surface representations. Journal of Verbal Learning \& Verbal Behavior, 23, 3-22.

Stewart, F., Parkin, A. J., \& Hunkin, N. M. (1992). Naming impairments following recovery from herpes simplex encephalitis: Category-specific? Quarterly Journal of Experimental Psychology, 44A, 261-284.

TYLER, L. K., \& Moss, H. E. (1997). Functional properties of concepts: Studies of normal and brain-damaged patients. Cognitive Neuropsychology, 14, 426-486.

Vandenberghe, R., Price, C., Wise, R., Josephs, O., \& Frackowiak, R. S. J. (1996). Functional anatomy of a common semantic system for words and pictures. Nature, 383, 254-256.

Van Orden, G. C., Jansen op de HaAr, M. A., \& Bosman, A. M. T. (1997). Complex dynamic systems also predict dissociations, but they do not reduce to autonomous components. Cognitive Neuropsychology, 14, 131-166.

Van Orden, G. C., Johnston, J. C., \& Hale, B. L. (1988). Word identification in reading proceeds from spelling to sound to meaning. Journal of Experimental Psychology: Learning, Memory, \& Cognition, 14, 371-386.

WARRINGTON, E. K. (1975). The selective impairment of semantic memory. Quarterly Journal of Experimental Psychology, 27, 635-657.

WARRINGTON, E. K., \& MCCARThY, R. (1983). Category specific access dysphasia. Brain, 106, 859-878.

WARRINGTON, E. K., \& MCCARThy, R. (1987). Categories of knowledge: Further fractionation and an attempted integration. Brain, 100, 1273-1296.

Warrington, E. K., \& Shallice, T. (1979). Semantic access dyslexia. Brain, 102, 43-63.

Warrington E. K., \& Shallice, T. (1984). Category-specific semantic impairments. Brain, 107, 829-853.

WERNICKE, C. (1989). Neurology: Recent contributions on aphasia. Cognitive Neuropsychology, 6, 547-569. (Original work published 1886)

Wise, R., Chollet, F., Hadar, U., Fiston, K., Hoffner, E., \& FrackOWIAK, R. (1991). Distribution of cortical neural networks involved in word comprehension and word retrieval. Brain, 114, 1803-1817.

ZiNGESER, L., \& BERNDT, R. S. (1988). Grammatical class and context effects in a case of pure anomia: Implications for models of language processing, Cognitive Neuropsychology, 5, 473-516.

\section{NOTES}

1. Functional components could also be distinguished neurochemically. However, since all the relevant evidence available to us-lesion site, PET, and fMRI data - concerns spatial segregation of components, we will be concerned only with neuroanatomical distinctions.

2. Currently, there is ongoing debate concerning the need to separate input phonology and input orthography, with some models supporting separate input pathways (e.g., Coltheart, Curtis, Atkins, \& Haller, 1993) and other models supporting distributed representations that do not require the representation of orthographic word forms (e.g., Plaut, McClelland, Seidenberg, \& Patterson, 1996). This issue is too complex to review here. However, we will assume that input orthography and input phonology are represented separately since this assumption provides us with a parallel configuration to our assumptions about output phonology and orthography, discussed later in the paper (see also note 15 for further comment on the relationship between assumptions for input and for output and how this may relate to the issue of separate [input and output] phonological and orthographic stores).

3. Attempts have been made to use distributed network models to simulate the performance of patients who present with surface dyslexia (e.g., Patterson, Seidenberg, \& McClelland, 1989; Plaut et al., 1996). Contrary to the authors' claims, however. these attempts have not been very successful in accounting for the full range of patient performance (see, e.g., Coltheart et al., 1993) 
4. The assumptions concerning routes of access to meaning are not common to all models of multiple-modality semantics but are specific to the model described by Shallice, as depicted in Figure 2 (see also Warrington \& McCarthy, 1987).

5. Unless otherwise noted, levels of performance for patients will always refer to proportion correct.

6. Riddoch and Humphreys (1987) questioned the magnitude of the difference in performance between the different modalities of input for at least one of the modality-specific semantic memory deficit patients studied by Warrington (1975). When performance was collapsed across all the probe question tasks, rather than each probe question being examined individually, A.B.'s overall performance was $112 / 160$ for picture input and 109/160 correct for auditory input (E.M. showed a stronge difference in performance, however: $132 / 160$ for picture input and $104 / 160$ for auditory input). Riddoch and Humphreys pointed out that both patients performed equally well or better with auditory input than with picture input when the question was one that could not be answered by information provided in the picture ("Is it English?"). All the other probe questions used by Warrington could have been answered on the basis of information available in the picture

7. Although they presented 4 patients, only 2 of these patients were studied extensively (J.B.R., S.B.Y.), and we will focus on them. The other 2 patients (K.B., I.N.G.) were very impaired and were tested on a subset of comprehension tasks only. They did, however, show a similar pattern of selective deficits for living things on these tasks.

8. Although the terminology refers to "visual" and "functional" semantic information, the terms are misleading since they have come to be short-hand terms for "perceptual" and "nonperceptual" knowledge. For example, the sound an animal makes is considered perceptual knowledge and the country from which an animal comes is considered nonperceptual knowledge. Thus, type of knowledge does not refer to only visual or only functional knowledge, but more generally to perceptual and nonperceptual knowledge.

9. This model is a more "general" example of the sensory/functional theory but is the "received" view in the literature. The model proposed by Warrington and colleagues distinguishes first between visual and verbal semantics and then, within each system, perceptual and nonperceptual knowledge.

10. It is important to note that even when categories have been equated for familiarity, frequency, and visual complexity, there are more cases reported that have a deficit to animals/living things than those that have a deficit to nonanimals/nonliving things, a fact that becomes important in attempting to explain category-specific deficits (see below). However, some researchers have argued that other factors such as age of acquisition and imageability can influence performance with category-specific items and may account for the apparent discrepancy in the number of cases that present with deficits to animals/living things as compared with nonanimals/nonliving things (e.g., Lambon-Ralph et al., 1998). Lambon-Ralph et al. claimed that animate concepts are acquired at an earlier age than nonanimate concepts and are more imageable, which could lead to better performance with animate items. While the point is well taken that other factors such as age of acquisition and imageability may influence performance and could lead to spurious identification of category-specific deficits, this explanation cannot account for the greater number of cases with deficits to animals/living things. In fact, this explanation would predict just the opposite since earlier age of acquisition and greater imageability would make animals the "easier" category (although at the same time this category has been shown to be less familiar than nonanimate categories and claimed to be the "harder" category). Thus, this "easier" category should not be expected to be identified as the "deficient" category in the majority of cases.

11. Although we are suggesting that writing and speaking can occur independently, we are not claiming that they must occur independently. Evidence that supports a role of phonology in writing is not contradictory to our arguments here. We are only suggesting that writing and speaking do not have to rely on each other; that is, phonology does not have an obligatory role in successful writing.

12. The data from E.A. do not allow us to rule out completely the possibility that he was activating a partial phonological code when attempting to orally name a picture and that this partial phonological acti- vation could be used to support his written naming. Although we cannot conclusively state that E.A. was not activating some lexical phonology in naming, there is some evidence to suggest that he was not getting much, if any, phonological information that could then be used to support successful writing. First, E.A. rarely made phonological errors in naming, suggesting that his deficit was not one of postlexical phonological output processing (i.e., there is no evidence that he successfully retrieved any of the phonological information), and he did not show any effects of phonological variables on naming. Second, E.A. would often produce two different responses in the different modalities when attempting to name at the same time as he was performing the naming task (i.e., when writing a name he would say a different name).

13. W.M.A. was also tested on a double naming task within the same modality. In this task, he always produced the same responses in the two trials. Thus, different responses were produced only across different modalities of output. The contrast in results in the two tasks suggests that the different responses produced in speaking and writing are not merely the result of independent attempts at naming but, rather, reflect the fact that different modalities are implicated.

14. Shelton and Weinrich (1997) developed a similar argument for the role of phonology in reading comprehension. Their patient, E.A., was shown to have little support from sublexical and lexical phonological information for input processing but demonstrated quite good reading comprehension. This pattern of performance does not support an obligatory role of phonology in reading comprehension (see also Coltheart \& Coltheart, 1997; Hanley \& McDonnell, 1997; but see Van Orden, Jansen op de Haar, \& Bosman, 1997, for commentary).

15. These data may also contribute to our understanding of input phonology and orthography. As mentioned earlier (see note 2), there is ongoing debate as to whether or not separate word forms are needed to represent input phonology and orthography or whether input processing can be represented in one distributed network. If one distributed network were used to represent input processing, it would likely be the case that one distributed network would represent output processing (or even that the same network would be used for input and output processing). Yet the data reported here support separate representations for output phonology and output orthography. It has yet to be demonstrated whether or not a distributed network of either speaking or writing can handle the dissociations in speaking and writing described here. And-more challenging -is the determination of whether or not one distributed network could handle all the findings from input processing as well as output processing.

16. Patients who make semantic errors in only one modality of output might be argued to have a semantic deficit that reveals itself only in the impaired output modality if degraded semantic information could not strongly address degraded information for output in the impaired modality. However, for this argument to work we would have to assume that the impoverished semantic information is enough to activate the correct output (even though the semantic information is degraded) in the unimpaired output modality. This argument does not seem likely given the differential levels of performance between the two output modalities. In at least some patients, performance in the unimpaired modality is perfect. This suggests that they can accurately access unimpaired semantics, which allows them to produce the correct name on every trial. It would be difficult to argue, for example, that a patient can perform perfectly on an oral naming task because he/she is unimpaired in speaking and stitl has a semantic impairment.

17. Rapp and Caramazza (1997) reported a patient who demonstrated impaired verbal production of open-class words and impaired written production of closed-class words with spared noun production. Thus, there is some evidence that nouns and verbs are not the only grammatical class along which lexical output processing is organized

18. An account that represents grammatical class within each modalityspecific output lexicon (i.e., output lexicons are organized according to grammatical class) would have difficulty accounting for patients who perform similarly with a specific grammatical class in both modalities (e.g., poor naming of verbs in both speaking and writing).

19. There is another way in which a modality-specific grammatical class effect could arise. If we assume that objects and actions are represented separately in the semantic system, damage to the connections 
from semantic information about nouns or verbs to the modalityspecific output form could result in a modality-specific grammatical class effect (Caramazza \& Miozzo, 1998). Although this distinction does not require us to postulate a tripartite distinction between semantic, syntactic, and lexical output forms, there is other converging evidence to support this distinction, which is summarized below.

20. It might seem that determining the initial phoneme or final phoneme is much more difficult than gender decision, even in those cases where the phoneme decision is a forced-choice task (i.e., the patient only has two choices for phoneme decision, the same as gender decision). However, Caramazza and Miozzo ( 1997; see also Miozzo \& Caramazza, 1997) have demonstrated that correct gender decision is not dependent on correct phoneme decision and that phoneme decision is made with better-than-chance accuracy (by normal subjects). Thus, the lack of relationship between gender decision and phoneme decision is not because subjects are very good with gender decision and very poor with phoneme decision, but rather that the two do not depend on each other (are not correlated), and a subject is frequently correct with phoneme decision but incorrect with gender decision. If it were just ease of decision that was driving the lack of relationship between gender decision and phoneme decision, we would not expect the above patterns to obtain. And, one cannot account for Dante's performance with verb auxiliaries by using an explanation that depends on "ease of the task" since the number of different auxiliaries used in Italian ( $t w o)$ is the same as the number of different genders ( $t w o$ ).

21. Pulvermuller (1995) reviewed evidence suggesting that content words and function words were also processed and represented in neuroanatomically distinct areas.

22. Although Dell has not specifically stated that the "lemma" level of representation is modality neutral, he has stated that the lemma is "nonphonological" (Dell et al., 1997). Presumably, this implies that the lemma level is modality neutral since the lemma is assumed to be an abstract representation specified for grammatical information but clearly not for phonological (or, by extension, orthographic) information. This line of reasoning applies to other models of speech production as well (e.g., Bock \& Levelt, 1994; Roelofs, 1992).

(Manuscript received December 8, 1997; revision accepted for publication May 20,1998.) 